\title{
Axial Structures Within the Reelfoot Rift Delineated With Magnetotelluric Surveys
}

U.S. GEOLOGICAL SURVEY PROFESSIONAL PAPER 1538-K

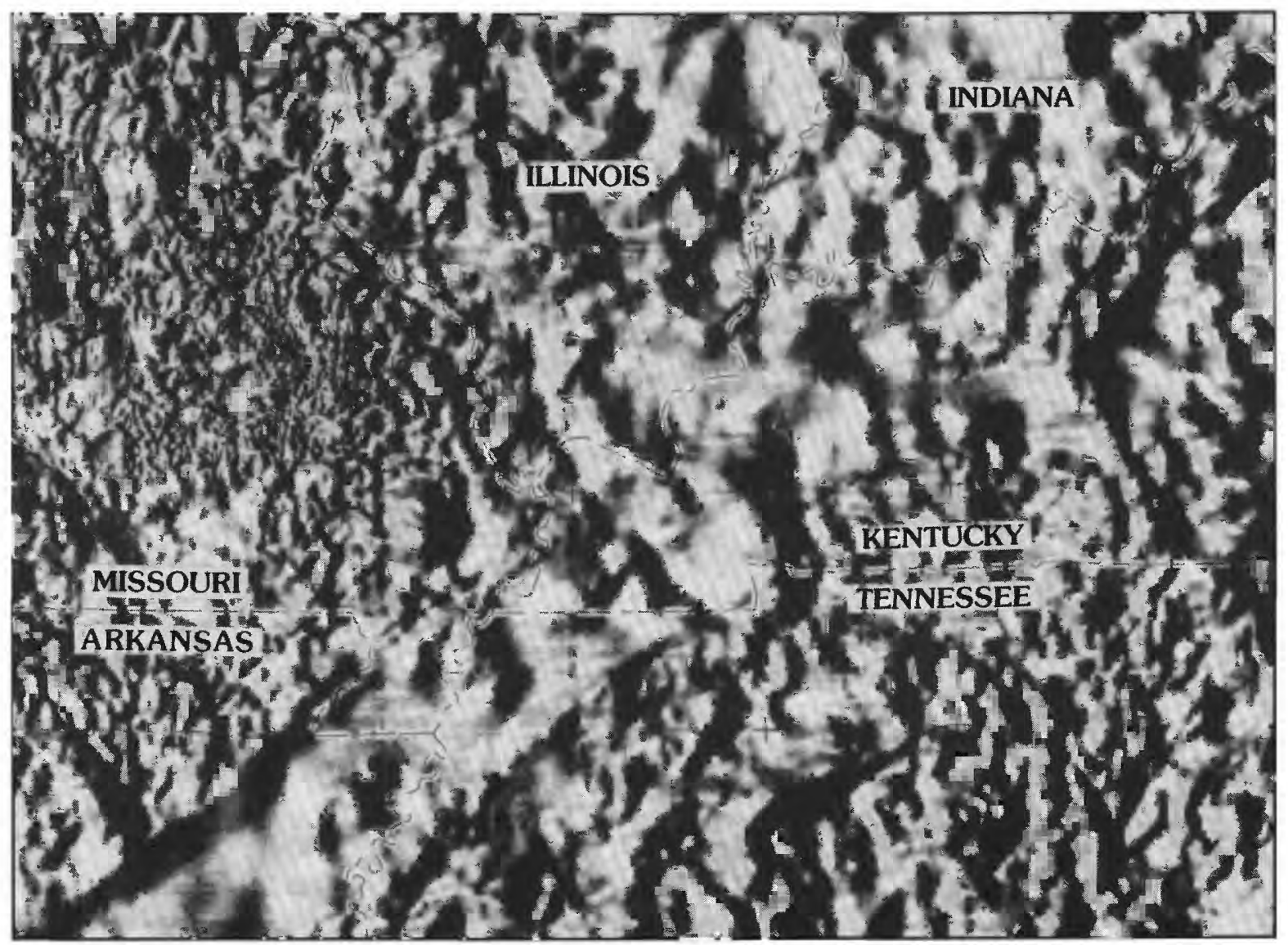


Cover. Gray, shaded-relief map of magnetic anomaly data. Map area includes parts of Missouri, Illinois, Indiana, Kentucky, Tennessee, and Arkansas. Illumination is from the west. Figure is from Geophysical setting of the Reelfoot rift and relations between rift structures and the New Madrid seismic zone, by Thomas G. Hildenbrand and John D. Hendricks (chapter $\mathrm{E}$ in this series). 


\section{Axial Structures Within the Reelfoot Rift Delineated With Magnetotelluric Surveys}

By Brian D. Rodriguez, William D. Stanley, and Jackie M. Williams

INVESTIGATIONS OF THE NEW MADRID SEISMIC ZONE

Edited by Kaye M. Shedlock and Arch C. Johnston

U.S. GEOLOGICAL SURVEY PROFESSIONAL PAPER 1538-K

UNITED STATES GOVERNMENT PRINTING OFFICE, WASHINGTON : 1996 


\title{
U.S. DEPARTMENT OF THE INTERIOR BRUCE BABBITT, Secretary
}

\author{
U.S. GEOLOGICAL SURVEY
}

Gordon P. Eaton, Director

\author{
For Sale by U.S. Geological Survey, Map Distribution \\ Box 25286, MS 306, Federal Center \\ Denver, CO 80225
}

\begin{abstract}
Any use of trade, product, or firm names in this publication is for descriptive purposes only and does not imply endorsement by the U.S. Government
\end{abstract}

\section{Library of Congress Cataloging-in-Publication Data}

Rodriguez, Brian D.

Axial structures within the Reelfoot rift delineated with magnetotelluric surveys / by Brian D. Rodriguez, William D. Stanley, and Jackie M. Williams.

p. $\mathrm{cm}$.-(Investigations of the New Madrid seismic zone : K)

(U.S. Geological Survey professional paper ; 1538-K)

Includes bibliographical references.

Supt. of Docs. no. ; I 19.16: 1538K

1. Geology, Structural-Missouri-New Madrid Region. 2. Magnetotelluric prospecting. I. Stanley, William D. II. Williams, Jackie M. III. Title.

IV. Series. V. Series: U.S. Geological Survey professional paper ; 1538-K. QE535.2.U6I59 1995 vol. K

[QE627.5.M8]

$551.2^{\prime} 2^{\prime} 09788985 \mathrm{~s}-\mathrm{dc} 20$

[551.8'09788985] 


\section{CONTENTS}

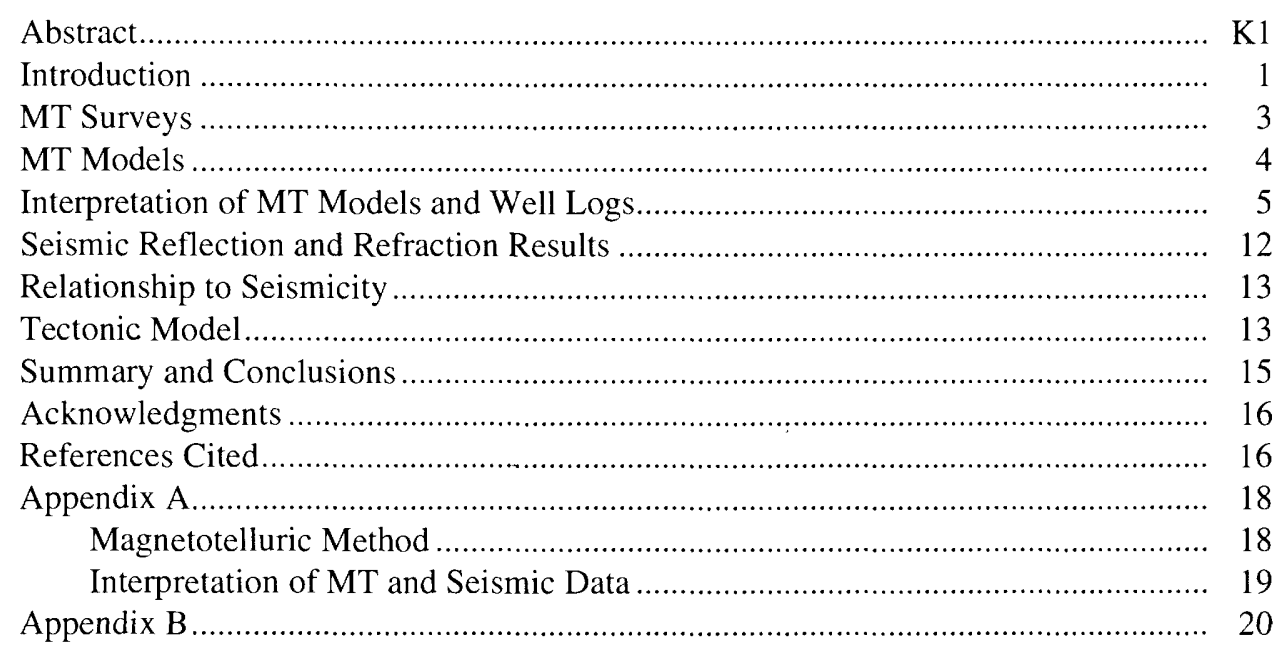

\section{FIGURES}

1. Index map for the Reelfoot rift-New Madrid region with key geologic features and locations of seismic and MT profiles.

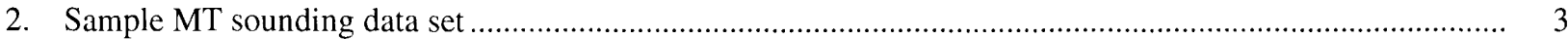

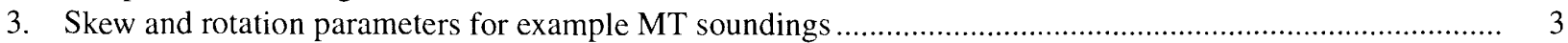

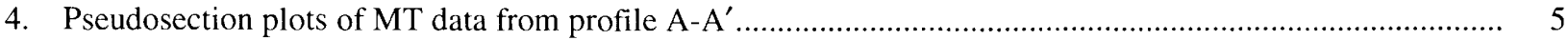

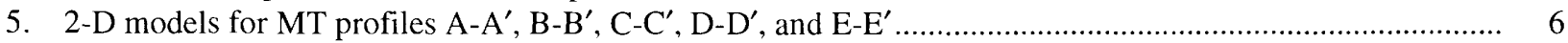

6. Generalized stratigraphy of Dow Chemical No. 1 Garrigan and No. 1 Wilson drill holes ............................. 7

7. Simplified resistivity logs and MT models for Dow Chemical No. 1 and No. 1 Wilson wells ....................... 8

8. Seismic reflection data and line drawing for seismic profile 2 ; line drawing for seismic profile 2 with MT model for profile E-E'; and line drawing for seismic profile 3 with MT model for profile $B-B^{\prime} \ldots \ldots . . \quad 10$

9. Tectonic reconstruction for a proposed axial horst in the Reelfoot rift .................................................. 14

10. Drawing showing possible generation of warped reflections by simple uplift ....................................... 15

B1-B10. Plots of observed data input to the 2-D inversion program and computed data for the derived model for each individual sounding on the five magnetotelluric profiles shown in figure 5 :

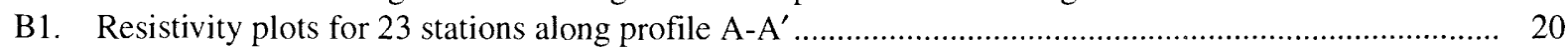

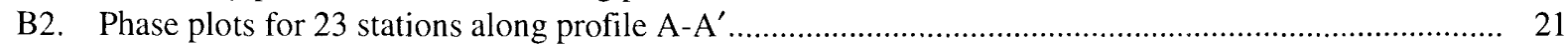

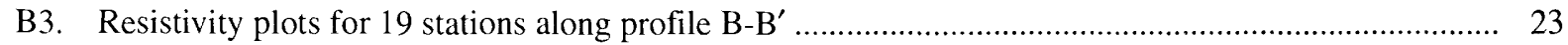

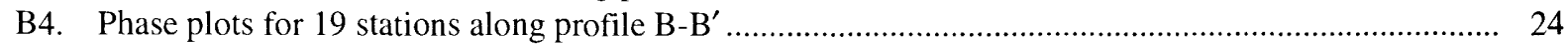

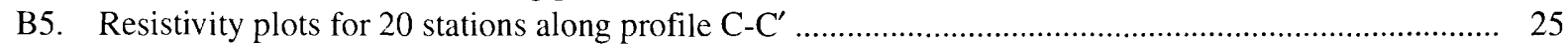

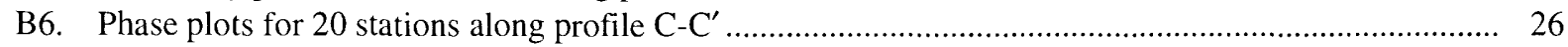

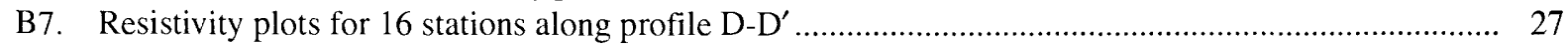

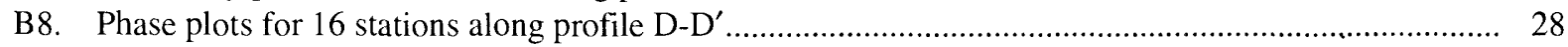

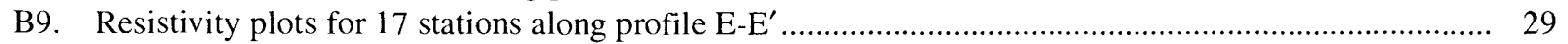

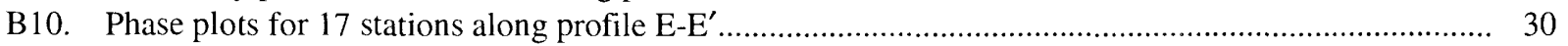





\title{
AXIAL STRUCTURES WITHIN THE REELFOOT RIFT DELINEATED WITH MAGNETOTELLURIC SURVEYS
}

\author{
By Brian D. Rodriguez, ${ }^{1}$ William D. Stanley, ${ }^{1}$ and Jackie M. Williams ${ }^{1}$
}

\begin{abstract}
The results of magnetotelluric (MT) surveys reveal structures associated with the Reelfoot rift, including an axial region of high resistivity that may indicate a previously unrecognized horst. Two-dimensional inversion methods were used to model the MT data, and three deep drill holes and seismic reflection data were used to help geologically constrain the MT models. The proposed horst occurs in the axial part of the Reelfoot rift and is generally coincident with a major, northeast-trending zone of seismicity. A linear region of upwarped and disrupted seismic reflections called the "Blytheville arch" is located near the proposed axial horst. The MT axial structure appears to terminate in the area of a northwest-trending belt of seismicity that extends southsoutheastward from New Madrid, Mo. However, the nature of the axial resistivity structure is uncertain in the New Madrid region because of the influence of a major axial intrusion that has been mapped in aeromagnetic surveys. This axial intrusion is interpreted from the MT models to have intruded into conductive, rift sedimentary rocks, resulting in three-dimensional geometries that complicate the MT analysis of the local rift structures.
\end{abstract}

\section{INTRODUCTION}

The Reelfoot rift is a possible failed rift arm, or aulacogen (Milanovsky, 1981; Howe, 1984) that probably formed in Late Proterozoic to Early Paleozoic time (Ervin and McGinnis, 1975; Thomas, 1991). Such rifts generally contain thick sedimentary sequences in the downdropped portion, and most are believed to have formed though horizontal extension that may extend into the middle and lower crust. A rift "pillow" of upwelled mafic material at deep crustal levels has been mapped in the Reelfoot rift and other rifts

${ }^{1}$ U.S. Geological Survey, Mail Stop 964, P.O. Box 25046, Denver Federal Center, Denver, CO 80225.
(Mooney and others, 1983; Hildenbrand, 1985). In this paper, we refer to the "rift" as the sedimentary-filled trough, recognizing that there are deeper structures required to compensate for the regional extension that caused the downdropping. The term graben is avoided because the nature of bounding faults has not been established in detail. We follow J.H. Illies (1981), who reserves the term "graben" in its original sense to denote only those linear depressions with parallel normal faults along which both central downdropping and shoulder upwarping have occurred.

The aeromagnetic data that first indicated the margins of the rift (Hildenbrand, 1985) also reveal plutons flanking the rift (fig. 1) and, at some places, within the rift. The rift is filled with basal Upper Precambrian to Cambrian clastic rocks. Upper Cambrian carbonate rocks (Bonneterre Formation) and shale (Elvins Group), Cambrian to Ordovician carbonate rocks (Knox-Arbuckle Group), and sedimentary rocks of Upper Cretaceous to Recent age that fill the Mississippi Embayment. The Blytheville arch is a 5- to $10-\mathrm{km}-$ wide structural high inferred from upwarped reflections flanking a zone of incoherent acoustic energy on seismic reflection records (Hamilton and McKeown, 1988). The arch is truncated by a post-Ordovician erosional surface. In the Reelfoot rift between Marked Tree, Ark., and Caruthersville, Mo., the modern seismicity coincides with this disturbed zone (fig. 1). McKeown and others (1990) have ascribed the arch's formation to diapirism. In addition, evidence for ancient and recent overpressure within the rift has been found (Diehl and McKeown, 1991) and may be another factor in formation of the arch.

The northeast-trending seismic zone (fig. 1) between Marked Tree, Ark., and Caruthersville, Mo., intersects a broader, northwest-trending zone of more intense seismicity that extends between Dyersburg, Tenn., and New Madrid, Mo. Another seismicity trend continues subparallel to the northwestern margin of the Reelfoot rift from New Madrid northeastward (fig. 1). The large earthquakes of 1811-12 are believed to have been located in the region between Marked Tree and Blytheville, Ark., and near New Madrid, Mo. (Nuttli, 1973). 


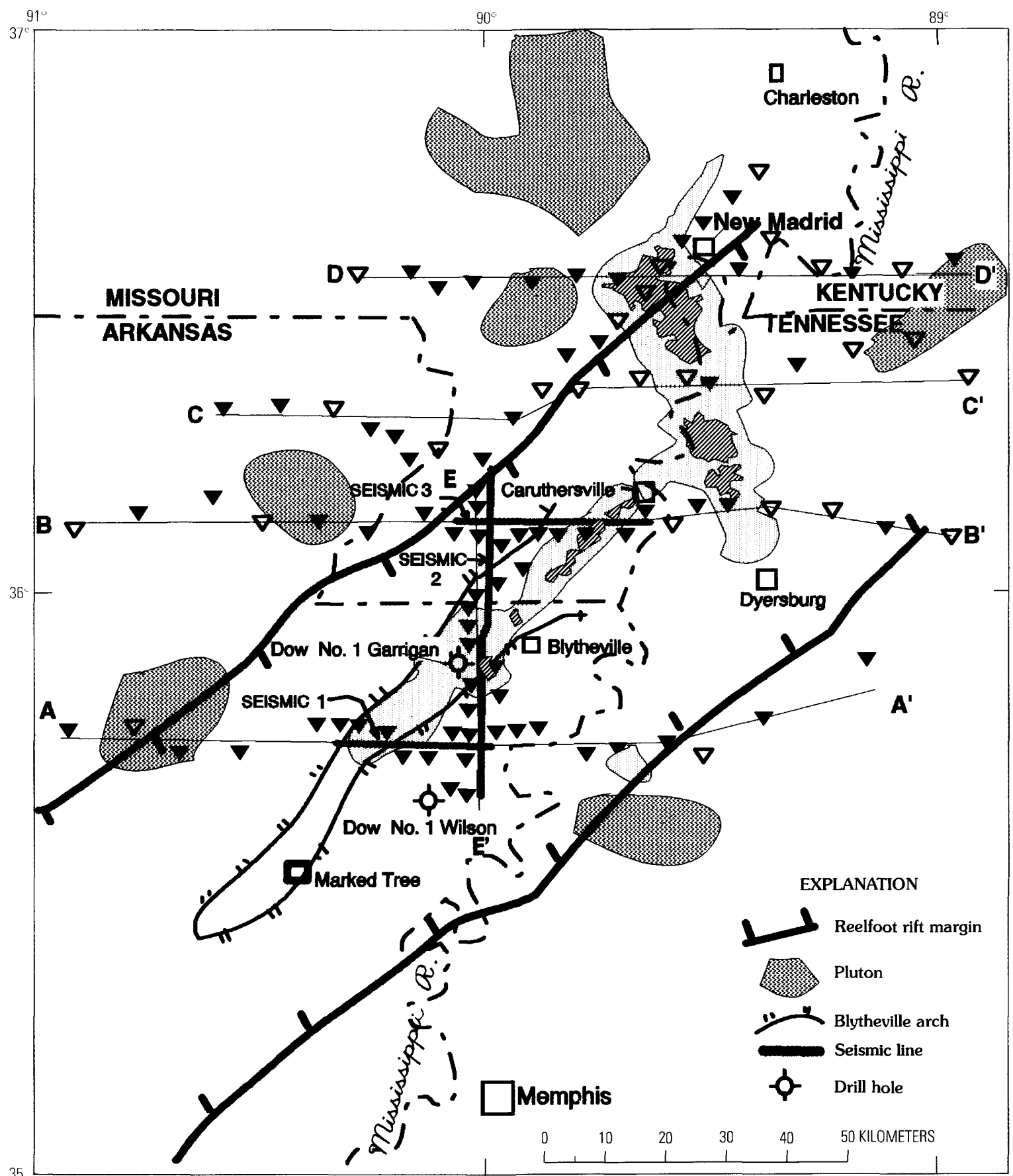

Figure 1. Index map for the Reelfoot rift and New Madrid region, adapted from McKeown and others (1990). Shown are rift margins and plutons determined from magnetic data by Hildenbrand (1985); Blytheville arch from Hamilton and McKeown (1988); epicenter density of 1973-88 seismicity (from Hamilton and Johnston, 1990); seismic reflection profiles from Hamilton and McKeown (1988); and selected drill holes. Magnetotelluric (MT) soundings are denoted by the inverted triangles; solid triangles are soundings with low three-dimensionality indicators; open triangles represent soundings with moderate to high three-dimensionality indicators (see text and fig. 3). Five MT profiles are discussed in the text, A-A', B-B', C-C', D-D', and E-E'. Earthquake densities for 1973-88 are denoted by stippled pattern where event densities were greater than one per square kilometer; cross-hatch pattern indicates densities of greater than two events per square kilometer; and no pattern indicates densities of less than one event per square kilometer. 


\section{MT SURVEYS}

One hundred and twenty magnetotelluric (MT) soundings were completed in the Reelfoot rift region to provide a geologic image of the subsurface through the study of changes in rock resistivity. Of particular interest were structural details of the Reelfoot rift and the deep crust and mantle beneath the sedimentary fill. The MT studies were part of a concentrated study of the New Madrid seismic zone that also included seismic refraction and wide-angle seismic profiling; high-resolution seismic reflection profiling; paleomagnetic studies; gravity, airborne magnetic and electromagnetic surveys; and seismicity, stress, geochemical, and geological studies.

The MT method employs natural electric and magnetic signals from ionospheric sources and lightning energy to determine tensor resistivities in the Earth's subsurface. In our MT surveys, signals at frequencies from 0.001 to $300 \mathrm{~Hz}$ were measured with U.S. Geological Survey-designed instrumentation and processed in real time with a computer that controlled the MT system. The recorded time-series data were transformed into the frequency domain using Fourier analysis and cross-spectral techniques. These techniques were used to determine a resistivity and phase tensor at each of the 120 measurement sites. Assuming a two-dimensional (2-D) Earth, the tensor can be rotated to maximum and minimum resistivity directions, and propagation modes for the signals are then decoupled into transverse magnetic (TM) and transverse electric (TE) modes that are equivalent to measurement of resistivity with the electric field directed across the strike and along the strike of the geologic structures, respectively. The MT method utilizes the fact that attenuation of electromagnetic fields in the Earth (or other conductors) is proportional to the square root of frequency times the conductivity (reciprocal of resistivity). This means that high-frequency signals are attenuated at shallow depth and lower frequency signals penetrate deeper, with the result that information on shallows rocks is contained in the highfrequency part of the MT sounding curves and information on deeper rocks is in the lower frequency parts of the sounding curves. This frequency-dependence of signal penetration is known as the "skin depth" effect.

Both resistivity and phase values are used in the modeling process. Sample plots of tensor resistivity and phases for the Reelfoot rift data are shown in figure 2. If data are obtained over 3-D structures, then the skew (fig. 3) of the tensor will have significant values, whereas for an exactly 2 D structure, the skew will be zero. Most of the data from the survey had low skew values, typically $0.1-0.3$, but, in the northeastern part of the survey area, skew values were much larger, from 0.3 to 1 . Associated with these high skew values is a departure from the typical northeast rotation azimuth of the tensor principal direction with respect to a north azimuth, as indicated in figure 3 . The significance of the high skew
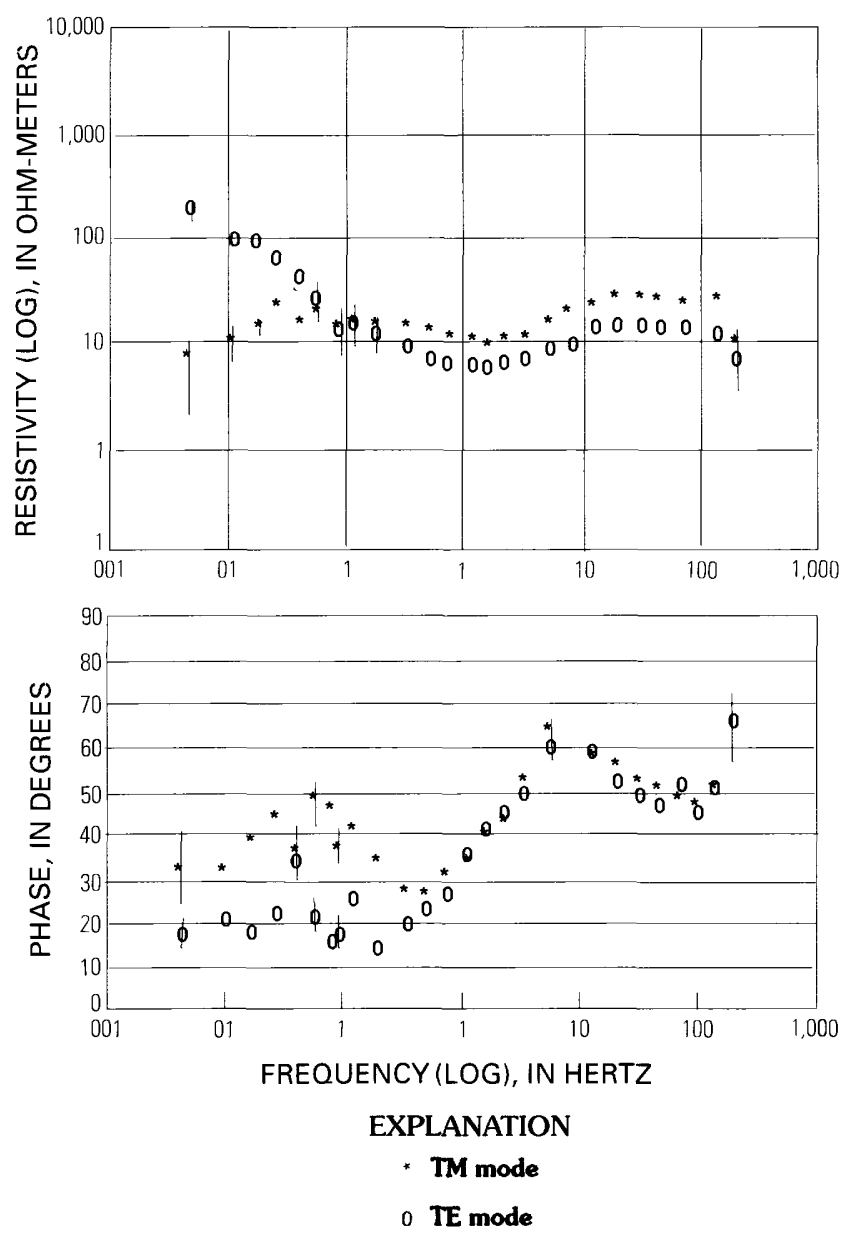

Figure 2. Sample magnetotelluric (MT) sounding data set from profile $A-A^{\prime}$ of figure 1 . Resistivity values are plotted in the upper graph and phase values in the lower graph. TM, transverse magnetic; TE, transverse electric.

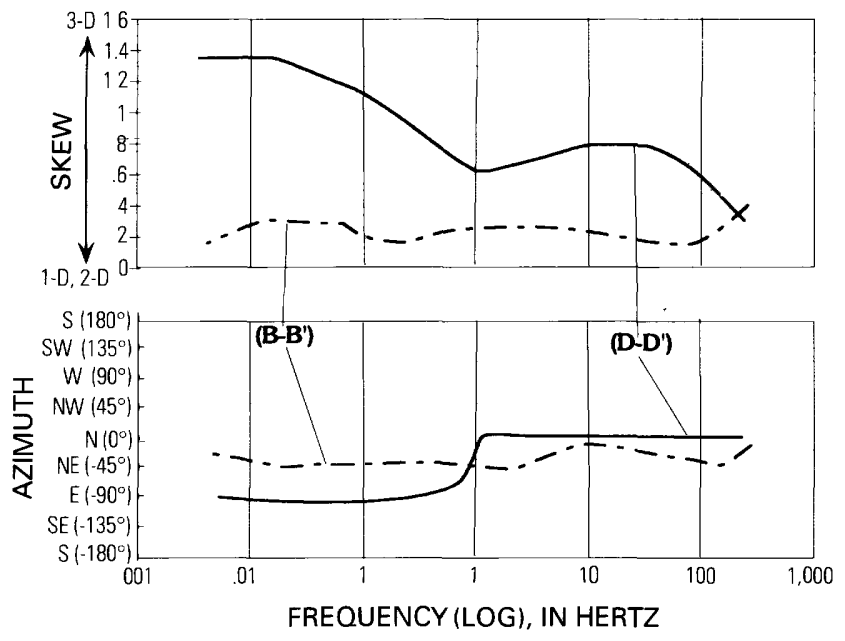

Figure 3. Skew of the impedance tensor and principal rotation direction of the tensor for typical magnetotelluric (MT) soundings on the eastern half of profiles B-B' and D-D'. 
values and change in rotation directions is discussed in a subsequent section.

Silicate minerals, which make up most rocks in the Earth's crust, are highly resistive. and conduction paths usually occur through the conductive fluids, clay minerals, or metallic-ore minerals in the rocks. Increased temperatures can raise the activation energy of minerals in rocks and enhance ionic conduction, thereby decreasing resistivities. Temperature is not a controlling factor in the upper $10 \mathrm{~km}$ of the Reelfoot rift due to low heat-flow values, and resistivities are largely controlled by the porosity and salinity of the rocks, as well as by their clay content. In general, the younger sedimentary rocks in the rift region have high clay content, large porosity, and moderate to high salinities, making them quite low in resistivity $(2-30 \mathrm{ohm}-\mathrm{m})$. Older sedimentary rocks have reduced porosity and minor clay content; thus, they are more resistive (30-500 ohm-m). A more extensive introduction to the MT method and a discussion of rock properties in included in Appendix A of this report.

\section{MT MODELS}

The MT data were modeled with a 2-D inversion algorithm (Smith and Booker, 1991) called the rapid relaxation inverse (RRI) because of similarities to classical relaxation solutions and because of its great operational speed. This method, which is one to two orders of magnitude faster than more conventional methods of 2-D inversion, utilizes approximate partial derivatives of MT data with respect to the conductivity directly beneath the measurement site and ignores cross-terms of horizontal field-gradients and conductivity gradients. Effectively, the iteration process involves intermediate 1-D inversions that are used to construct a 2-D model needed to obtain new sets of model residuals from 2-D forward calculations for subsequent iterations. The algorithm has been tested with numerous syntheticmodel data sets and has proven to converge to the correct geometry of these models. In our experience with data from this survey and several others, we have found that the RRI method provides a rapid means of 2-D modeling that achieves excellent fits to the observed data. The other advantage to the RRI inversion method stems from the use of a minimum-structure criteria (Smith and Booker, 1988), in which the algorithm applies a selected number of final iteration steps in which the complexity of the model is reduced while maintaining an overall good fit to the data. These latter steps substantially reduce model artifacts in the final solution. In addition, the effects of near-surface resistivity anomalies that cause "static shifts" (Sternberg and others, 1988) of the data can be reduced by utilizing a distortion matrix in the program. This shift was manually corrected in five of the more severely shifted soundings by using comparisons with unshifted data nearby. For the remainder of the data, we used the technique of Booker (1991), which involves determining the distortion coefficients using a joint TE-TM inversion first, followed by a TE inversion only. No resolution statistics are provided on the uniqueness of the derived models, but, with the use of minimum-structure constraints, one can be assured that the totality of models that fit the data is reduced to a small set of simplest models. The program can be run with different starting models and error assumptions to more thoroughly investigate the range of possible models.

For our data, the inversion used a model grid with typically 70 columns and 35 rows of conductivity cells. Separate inversions of the TE- and TM-mode data were done, as well as joint inversion of both modes. For the structure of the Reelfoot rift, with a highly conductive linear channel composed of rift sedimentary fill, it was found that inversions of the TE data yielded models that were more consistent between MT profiles and with well logs than did inversions of the TM data. The TM mode involves currents that flow across the strike of the structures, and the inversion process is required to fit these currents at all stations along the profile. In contrast, the TE mode inversions can work more exclusively on the structures beneath an individual site. The result is that TE inversions are more sensitive to structures directly beneath the measurement site, whereas the TM inversions greatly average details across the structure. However, inversion of the TE-mode data has one key disadvantage: limited strike length of the rift affects low-frequency data; hence, the resolution of deeper structures (below the rift) is poor. The fits to the observed data were generally within measurement errors in the data. typically 3-10 percent. A comparison of the computed and observed data for profile $\mathrm{A}-\mathrm{A}^{\prime}$ is shown in figure 4 . The agreement between the observed and model data is excellent and is typical of the fits for the other profiles. The observed and computed data for individual stations on all five MT profiles are included in Appendix B of this report. Three-dimensional models of the rift using forward-modeling methods should be useful for refining details of the structure in the northeastern part of the study area, where the data clearly show severe departures from 2-D character.

Models for the four east-west profiles and the northsouth profile located in figure 1 are shown in figure 5 . The starting model for the inversions was a simple, pseudo-horizontally layered Earth designed for each individual profile based upon a 1-D model for each sounding; this starting model can be observed unchanged on the ends of the display of figure 5. The derived conductivity model has been simplified by using five ranges as shown in figure 5 . The MT method is very insensitive to high resistivities beneath a conductive section such as the Cretaceous and Tertiary sedimentary rocks that fill the Mississippi Embayment. Sensitivity analysis for 1-D and 2-D models in our study has shown that it is very difficult to accurately resolve resistivities greater than about $500 \mathrm{ohm}-\mathrm{m}$ in the upper crust; thus, the resistivities shown as greater than $500 \mathrm{ohm}-\mathrm{m}$ may be much larger. The MT data used in the models should have 


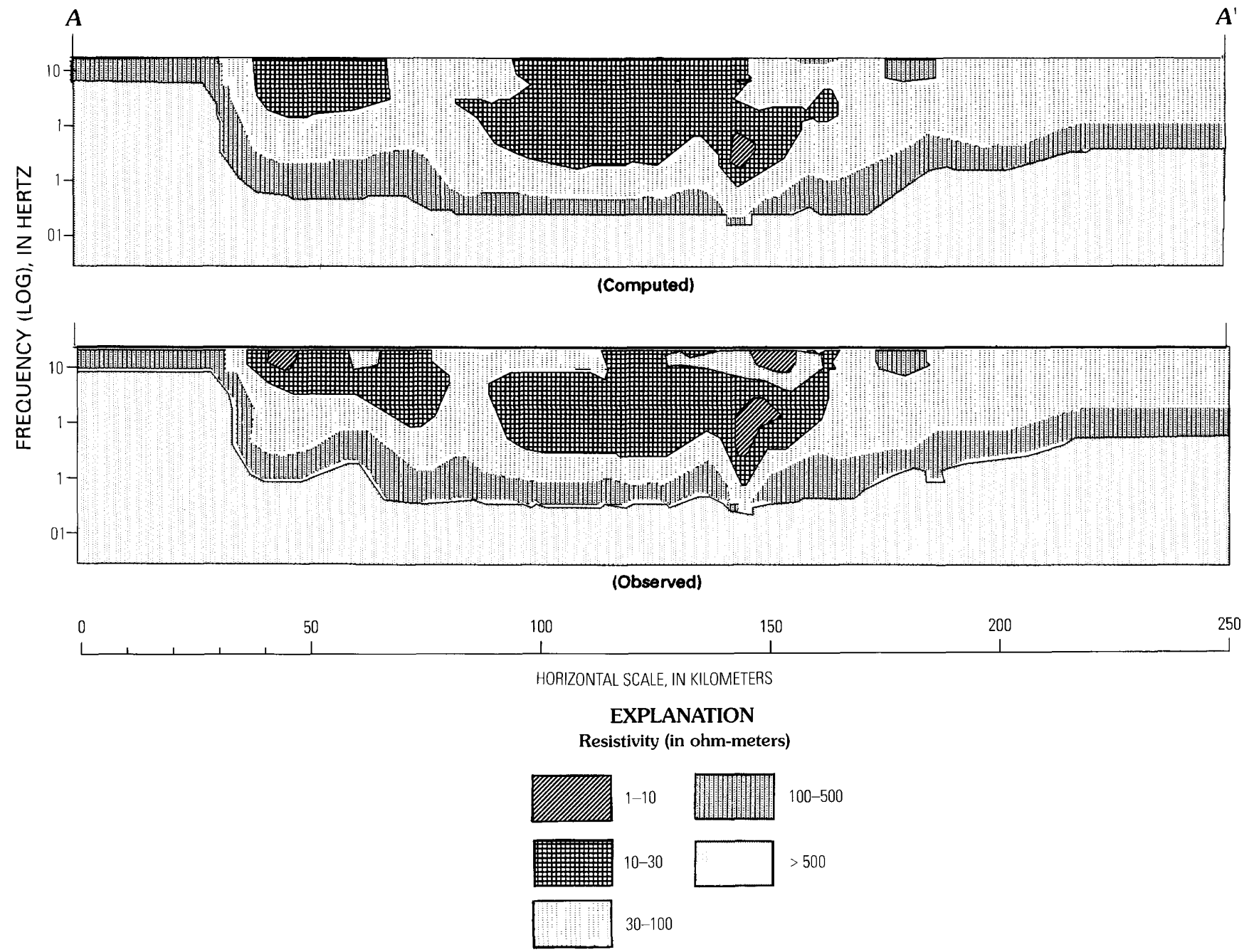

Figure 4. Pseudosection plots of observed magnetotelluric (MT) data from profile A-A' and computed data for the transverse electric (TE) inversion of this profile. The vertical axes of the plots are logarithmic frequency, which reflects the "skin depth" relationship of MT soundings, wherein the highest frequency data contains information about shallow rocks and the lower frequency data contains information on deeper rocks. The resistivity patterns are the same as those in the models of figure 5 , where the data have been mapped to depths and layer resistivities by the inversion algorithm.

delineated crust-mantle structures to depths greater than 40 $\mathrm{km}$, but our investigation of the resulting models indicates that the overpowering effects of the conductive sedimentary rocks in the Reelfoot rift and Mississippi Embayment make meaningful interpretation of middle-lower crust/mantle rift structures difficult. Based upon study of the models of figure 5 , but plotted to depths of $40 \mathrm{~km}$, we interpret that the crust has resistivities greater than $500 \mathrm{ohm}-\mathrm{m}$ at depths greater than a few kilometers and that no conductive zones that might be caused by magma or other fluids exist in significant thicknesses (probably less than $500 \mathrm{~m}$ ) in the deep crust. A combination of 3-D and newly acquired ultra-lowfrequency (as low as $0.0002 \mathrm{~Hz}$ ) MT data are being utilized to further investigate structures deeper than those shown in figure 5 .

\section{INTERPRETATION OF MT MODELS AND WELL LOGS}

The geological interpretation of the MT profile models in figure 5 has relied heavily on well logs from the Dow Chemical No. 1 Wilson and No. 1 Garrigan drill holes (fig. 6) and seismic reflection data. These two wells have been studied intensively by McKeown and others (1990), Diehl and McKeown (1991), and Collins and others (1992). The Dow Wilson well is located just east of the Blytheville arch, close to MT profile A- $\mathrm{A}^{\prime}$ (fig. 1), and the Dow Garrigan is actually located on the arch, just north of MT profile A- $\mathrm{A}^{\prime}$ (fig. 1). These two wells exhibit the stratigraphy of the region in detail, as shown in the chart of figure 6 (modified from F.A. McKeown, written commun., 1991). Approximately 

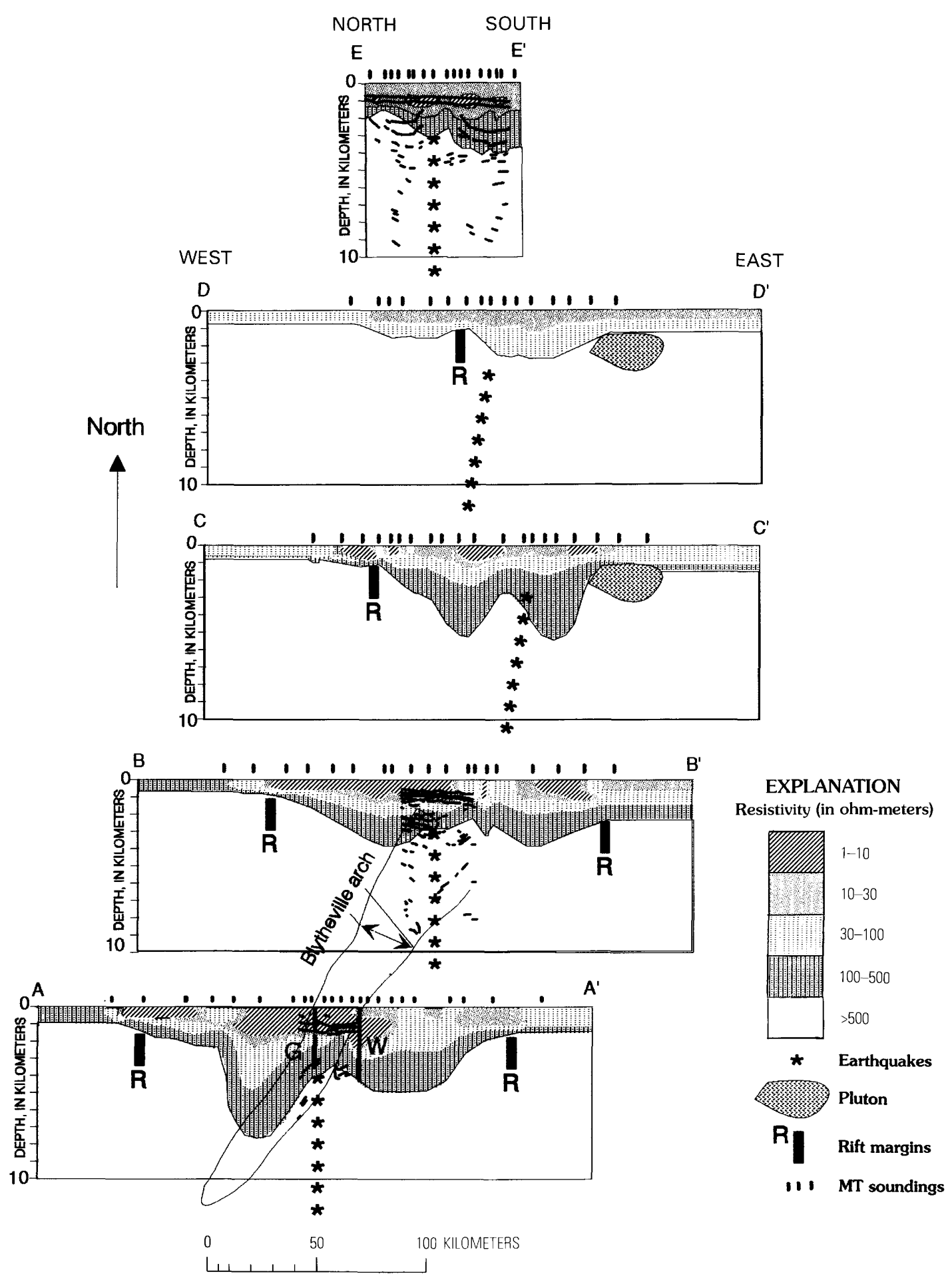

Figure 5. Final models for two-dimensional inversions of magnetotelluric (MT) data from profiles A-A', B$\mathrm{B}^{\prime}, \mathrm{C}-\mathrm{C}^{\prime}, \mathrm{D}-\mathrm{D}^{\prime}$, and E-E'. Most, but not all, of the soundings along the profiles were used (indicated by heavy ticks). Vertical exaggeration is $8: 1$. The combined view of all five profile models is shown in an approximately relative spatial position (except for $\mathrm{E}_{-} \mathrm{E}^{\prime}$ ). The approximate surface spatial relationship of the Blytheville arch to the MT profiles is shown on the models for $\mathrm{A}-\mathrm{A}^{\prime}$ and $\mathrm{B}-\mathrm{B}^{\prime}$. Line drawings of reflection data from seismic reflection profiles 1, 2, and 3 using a time-to-depth conversion velocity of $4 \mathrm{~km} / \mathrm{s}$ (see text) are superimposed on the models for MT profiles A-A', B-B', and E-E', respectively. Heavy, vertical lines on profile A-A' labeled "G" and "W" show the location and depths of the Dow Garrigan and Dow Wilson deep drill holes, respectively. Edges of the Reelfoot rift are interpreted from MT models. Pluton location, indicated on MT models C-C' and D-D', is sketched from the location noted in figure 1. The approximate location and attitude of zones of seismicity (from Chiu and others, 1991) are indicated by asterisks. 

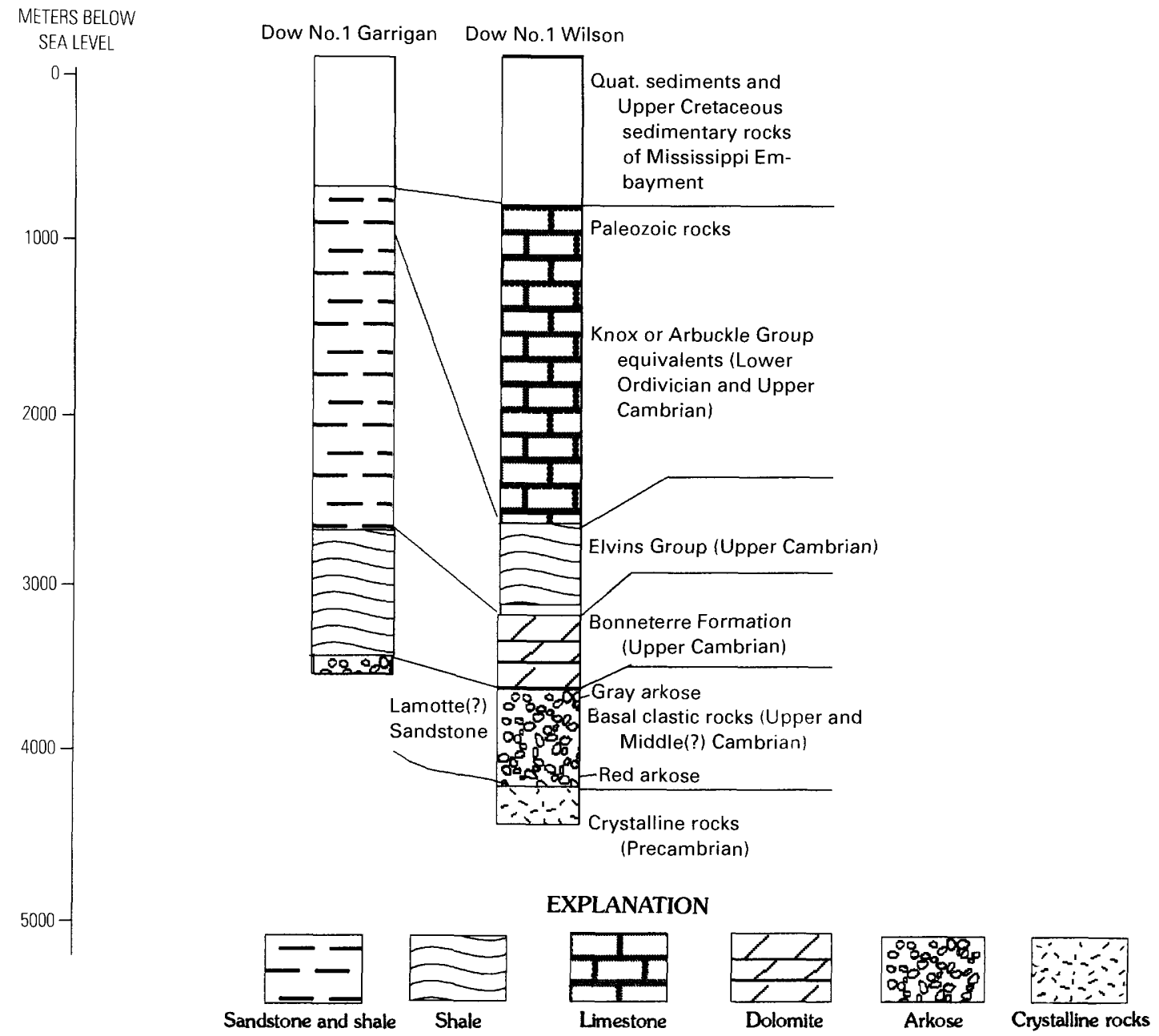

Figure 6. Generalized stratigraphy in the Dow Chemical No. 1 Garrigan and No. 1 Wilson drill holes. Adapted from F.A. McKeown (written commun., 1991).

600-800 m of Quaternary sediments and Upper Cretaceous sedimentary rocks of the Mississippi Embayment occur on top of an erosional surface in the Lower Ordovician KnoxArbuckle Group-equivalent limestones. Elvins Group rocks are largely shales in the Garrigan well but have more limestone content in the Dow Wilson well. Upper Cambrian dolomitic rocks of the Bonneterre Formation occur on top of basal arkoses of Upper and Middle Cambrian age. The Precambrian gneisses encountered in the Dow Wilson well form the basement for the Reelfoot rift.

The electrical resistivity logs from the Wilson and Garrigan drill holes are shown in figure 7. Ranges of resistivity from the well logs are indicated by the bold boxes at various depth intervals. The electrical resistivity logs indicate that the resistivities of the Cenozoic sedimentary rocks are 7-40 ohm-m and resistivities of the Cretaceous mudstones and sandstones that extend to depths of slightly less than $1 \mathrm{~km}$ are 3-20 ohm-m. The thick Knox-Arbuckle Group carbonate rocks in the Wilson drill hole have resistivities of 100-500 ohm-m, but a red clay unit at 2,500-m depth has a resistivity of 1-3 ohm-m. This red clay section generates key seismic reflections (fig. $8 A$ ) that are mappable throughout much of the area (McKeown and others, 1990). The resistivity distribution in the Wilson well from $2,700 \mathrm{~m}$ to $3,900 \mathrm{~m}$ is highly variable. The resistivities range from $30-900 \mathrm{ohm}-\mathrm{m}$ within the basal part of the Knox or Arbuckle Group equivalents, the Elvins Group, the Bonneterre Formation, and the upper part of the basal clastic sequence. The lower part of the basal clastic rocks and the Precambrian crystalline rocks have resistivities greater than $1,000 \mathrm{ohm}-\mathrm{m}$ in the Wilson well; thus, the MT data cannot be used to distinguish basal clastics from crystalline basement. This is unfortunate because interpretations of seismic reflection data are thought to possibly show several kilometers of these clastic rocks in parts of the rift (F.A. McKeown, oral. commun., 1991; Howe, 1984).

The upper two-thirds of the Elvins Group shales (from 800-m to 1,900-m depth) in the Garrigan drill hole has resistivities that range from 5-20 ohm-m, but the lower one-third (from $1,900 \mathrm{~m}$ to $2,400 \mathrm{~m}$ ) has significantly higher resistivities of $15-80 \mathrm{ohm}-\mathrm{m}$. The general resistivity values of 


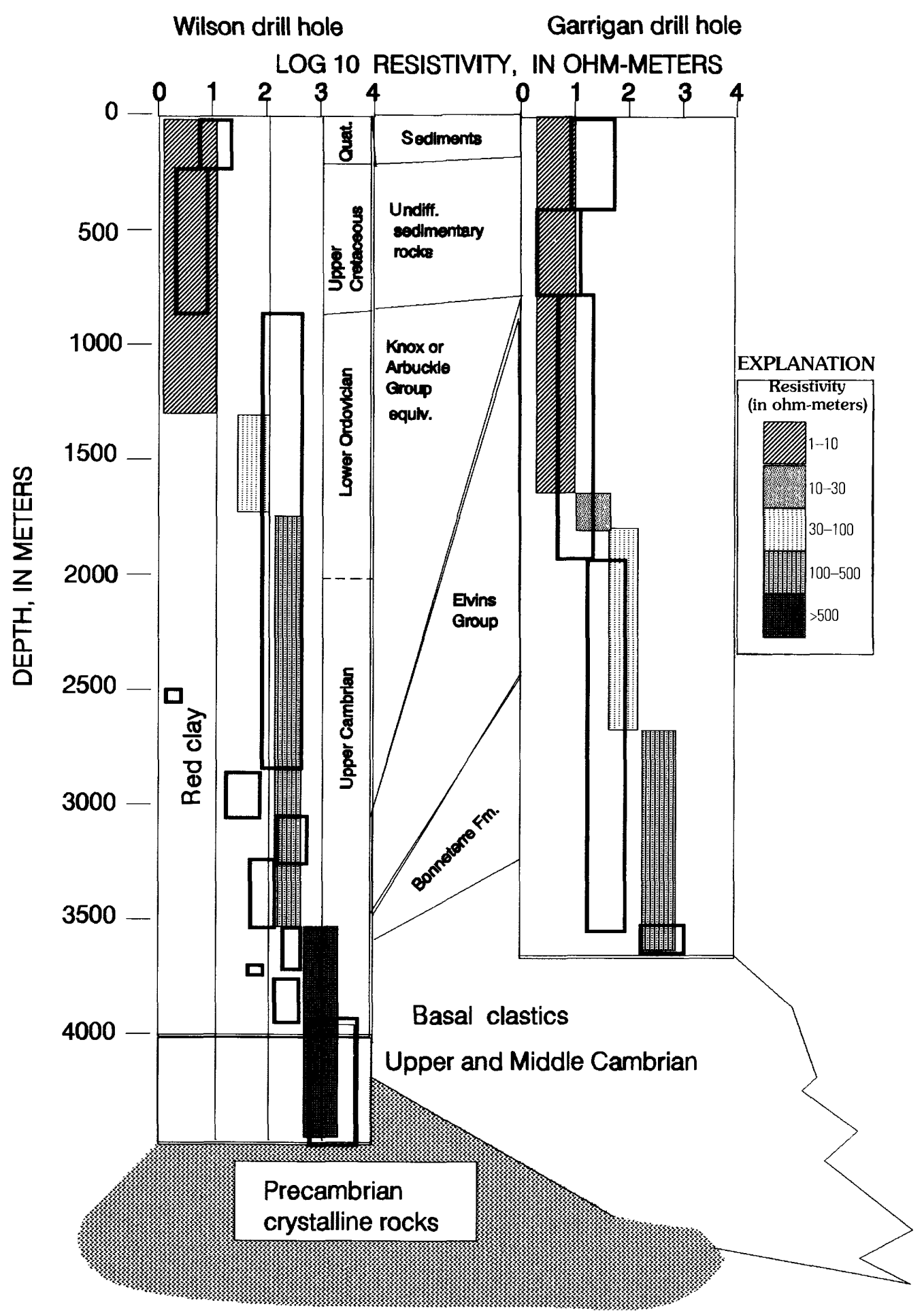

Figure 7. Simplified resistivity logs (bold, blank boxes) for ranges of resistivity at various depth intervals. Vertical slices from magnetotelluric (MT) models on profile $A-A^{\prime}$ at the projected location of the wells are superimposed on the well logs. Key geological formations are shown between electrical logs.

marine shales ranges from less than $1 \mathrm{ohm}-\mathrm{m}$ for clay-rich black shales with high carbon content to tens of ohm-meters in shales with small amounts of carbon (or carbon that has been oxidized). Based upon the higher resistivity character of the lower one-third of the Elvins Group in the Garrigan drill hole, we infer that this portion of the Elvins Group may have been deposited in shallow-water, oxidizing conditions. If the lower part of the Elvins Group represents a shallow-water, 
limy equivalent of the upper two-thirds of the Elvins in the Garrigan hole, then the vertical change in the resistivity of the Elvins Group shales may be evidence for progressive transition from limestones to deep-water shales in the Upper Cambrian. The much larger shale thickness in the Garrigan hole suggests that this drill hole is located closer to an Upper Cambrian depocenter than the Wilson hole. Basal clastics encountered in the Garrigan hole have resistivities of $500-1,000$ ohm-m.

We have projected the Wilson and Garrigan holes along strike $\left(\mathrm{N} .45^{\circ} \mathrm{E}\right.$.) onto MT profile A- $\mathrm{A}^{\prime}$ as indicated in figure 5. MT soundings could not be done at each individual well because of the influence of nearby power lines. Vertical slices from the models at the projected well locations indicated in figure 5 are plotted on the resistivity logs (fig. 7), with the same resistivity patterns used as in the model cross sections (fig. 5). Considering the low resolving power of the MT method, the agreement between the model and the well $\operatorname{logs}$ is very reasonable. This composite plot can be understood more easily if it is remembered that both plots represent ranges; thus, there is general agreement when the two plots touch each other. It is not expected that the ranges will completely coincide because the MT method measures a large volume of rock, whereas the well log measures only the variable fluid/rock environment in the drill hole. The MT method has relatively poor resolution, usually with a minimum error of 10 percent in the depth to a given layer; comparison with coincident MT-seismic refraction surveys in areas such as the Cascades in the Western United States (Stanley and others, 1990) show that the resolving power of the MT method for thick geologic units is generally similar to that of seismic refraction surveys.

A difference of about $400 \mathrm{~m}$ occurs between the well $\log$ and the MT models for the Wilson hole in regard to the thickness of the uppermost conductive section. This section corresponds to units younger than Paleozoic $(0-$ to $800-\mathrm{m}$ depth). The difference in thickness of the conductive sections on the resistivity log and MT model for the Wilson hole may be due to noncoincidence of the MT model profile and the drill hole location, but it may also be due to differences in measurement characteristics of the electrical-log tools and the MT sounding. The MT method measures an integrated value of the reciprocal of resistivity (conductivity) for individual beds multiplied by the thickness of the beds. Thus, a sequence of thin, low-resistivity beds in a formation can completely dominate the response in the MT data. For the Garrigan hole, the thick conductive section from $0-1,700 \mathrm{~m}$ on the MT model corresponds to both the post-Paleozoic Mississippi Embayment rocks and the upper part of the Elvins Group shales; there is better correspondence between the MT model and he resistivity log for this section than in the Wilson hole. For the remainder of the depth of the two drill holes, we consider that there is agreement between the MT models and the well logs, except for minor complexities from $3,000 \mathrm{~m}$ to $3.800 \mathrm{~m}$ in the Wilson hole and higher resistivities in the MT model (compared to the resistivity $\log$ ) for the 2,700- to 3,500-m interval in the Garrigan hole. This latter disagreement may be due to relief on the highresistivity, basement structure indicated between the projected locations of the Wilson and Garrigan holes.

The east-west MT profile models in figure 5 clearly define the margins of the rift. The conductive section of less than $30 \mathrm{ohm}-\mathrm{m}$ represents the poorly consolidated Quaternary-Cretaceous clay-rich sandstones and shales, KnoxArbuckle carbonates with highly saline pore fluids, and the upper parts of the Elvins. Units of 30-100 and 100-500 ohm$\mathrm{m}$ probably represent the remainder of the Knox-Arbuckle and Elvins Group rocks, the Bonneterre Formation, and the upper part of the basal clastics (based upon correlations of such resistivity units at the Dow Wilson well). Crystalline basement occurs about at the $>500$-ohm-m zone on profile $\mathrm{A}-\mathrm{A}^{\prime}$ at the location where we have projected the Dow Wilson well (fig. 5). We infer that this $>500$-ohm-m level in the models represents the approximate depth to crystalline basement elsewhere in the survey area.

Seismic reflection data show that the interface between the Cretaceous and Paleozoic units has much less relief than indicated by the MT models (fig. 5). The greater relief in the upper conductive section in the MT models is caused by several factors, including "static-shift" effects of near-surface resistivity anomalies, inversion and data artifacts, and, lastly, the variability of resistivity within formations caused by lateral changes in clay and salinity content. Because of the nature of the MT method, some of these effects propagate downward into the models below their depth of occurrence. Any direct correlation of the shape of anomalous zones in the upper part of the section with the shape of the basement units ( $>500 \mathrm{ohm}-\mathrm{m}$ ) may be artifacts of the static-shift effects on the model. However, the general shape of the "basement" horizon on the models does not correlate well with the shape of the upper conductive section. Therefore, we interpret that the MT models represent a valid representation of the true structure of Reelfoot rift, at least in the gross sense. The intrusive bodies along the margins of the rift that have been mapped with aeromagnetic data (fig. 1) were not detectable in the MT data because their resistivities were similar to that of the Precambrian gneisses that form the basement.

The most significant aspect of the models, apart from detailed information on the location of the rift margins, is the resistivity high at basement depths in the axial part of the rift. The general thickness of the sedimentary rocks that have resistivities less than $500 \mathrm{ohm}$-m along the four profiles varies from about $3 \mathrm{~km}$ on $\mathrm{D}^{-\mathrm{D}^{\prime}}$ to as much as $7 \mathrm{~km}$ on profile $A-A^{\prime}$. The resistive high along the center of the models for profiles A-A', B-B', and C-C' has a relief of about $3 \mathrm{~km}$. This axial resistivity high clearly follows the northeast-trending axis of the rift up to profile $\mathrm{C}^{-\mathrm{C}^{\prime}}$, but its location on profile D- $\mathrm{D}^{\prime}$ is ambiguous. The eastern ends of both profiles $\mathrm{C}^{-\mathrm{C}^{\prime}}$ and $D^{-} \mathrm{D}^{\prime}$ apparently cross a pluton that was interpreted from magnetic data (fig. 1) by Hildenbrand (1985). We believe 


\section{エ}

工

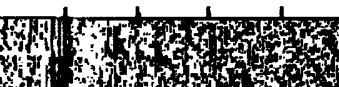

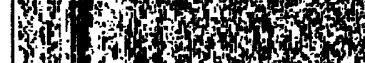
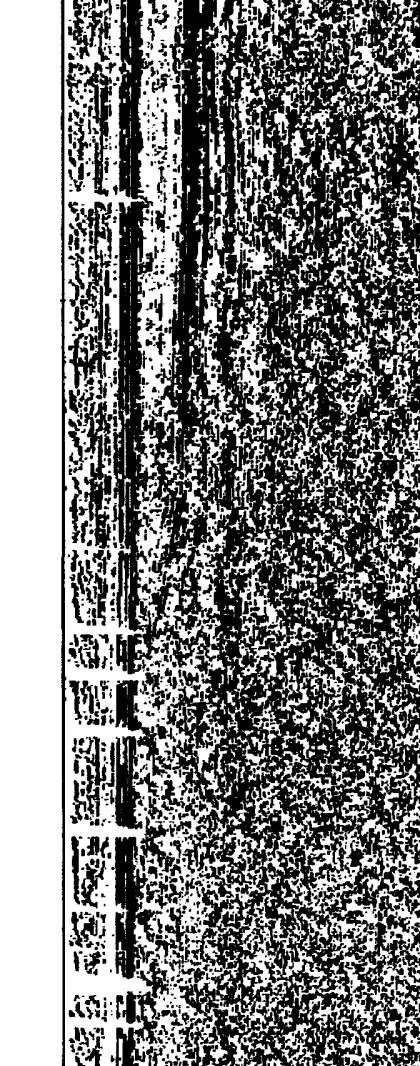

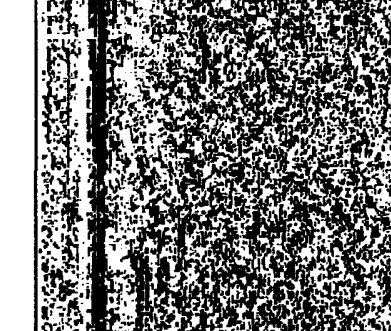
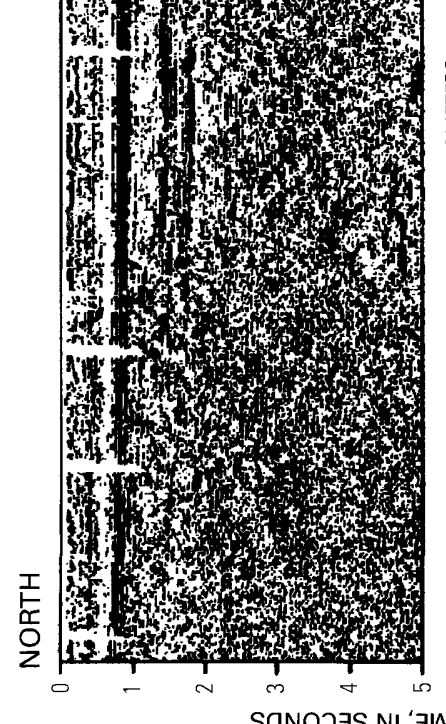

SONOJ

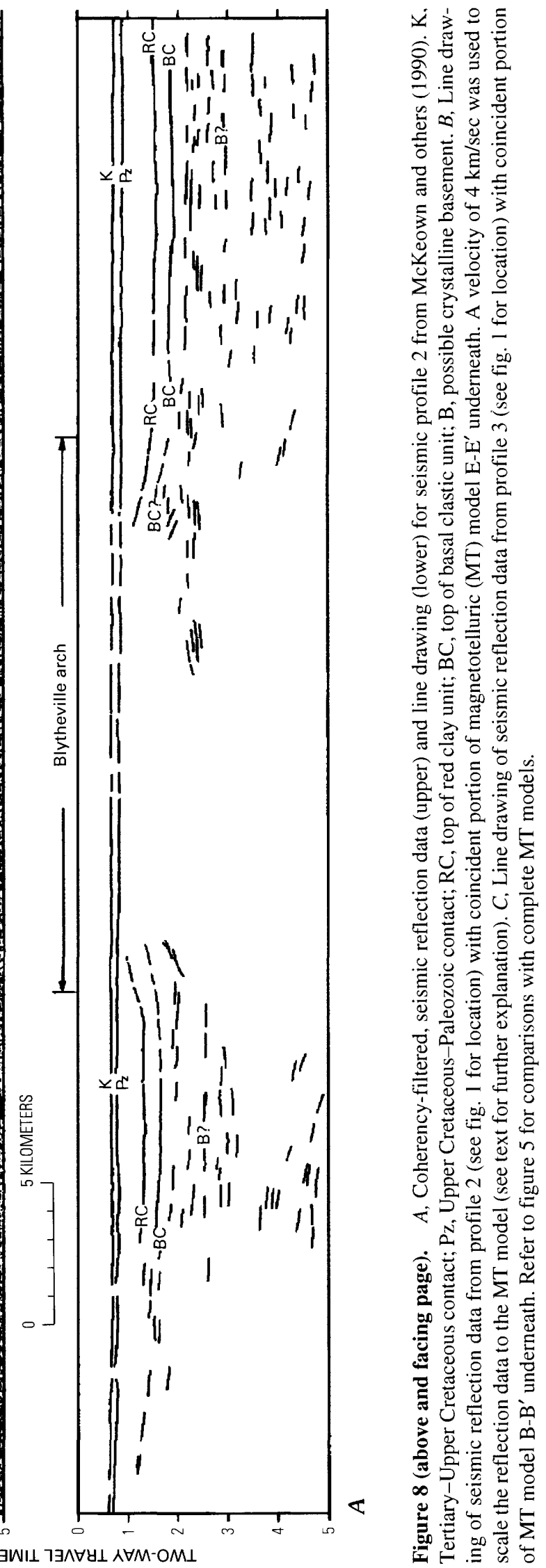




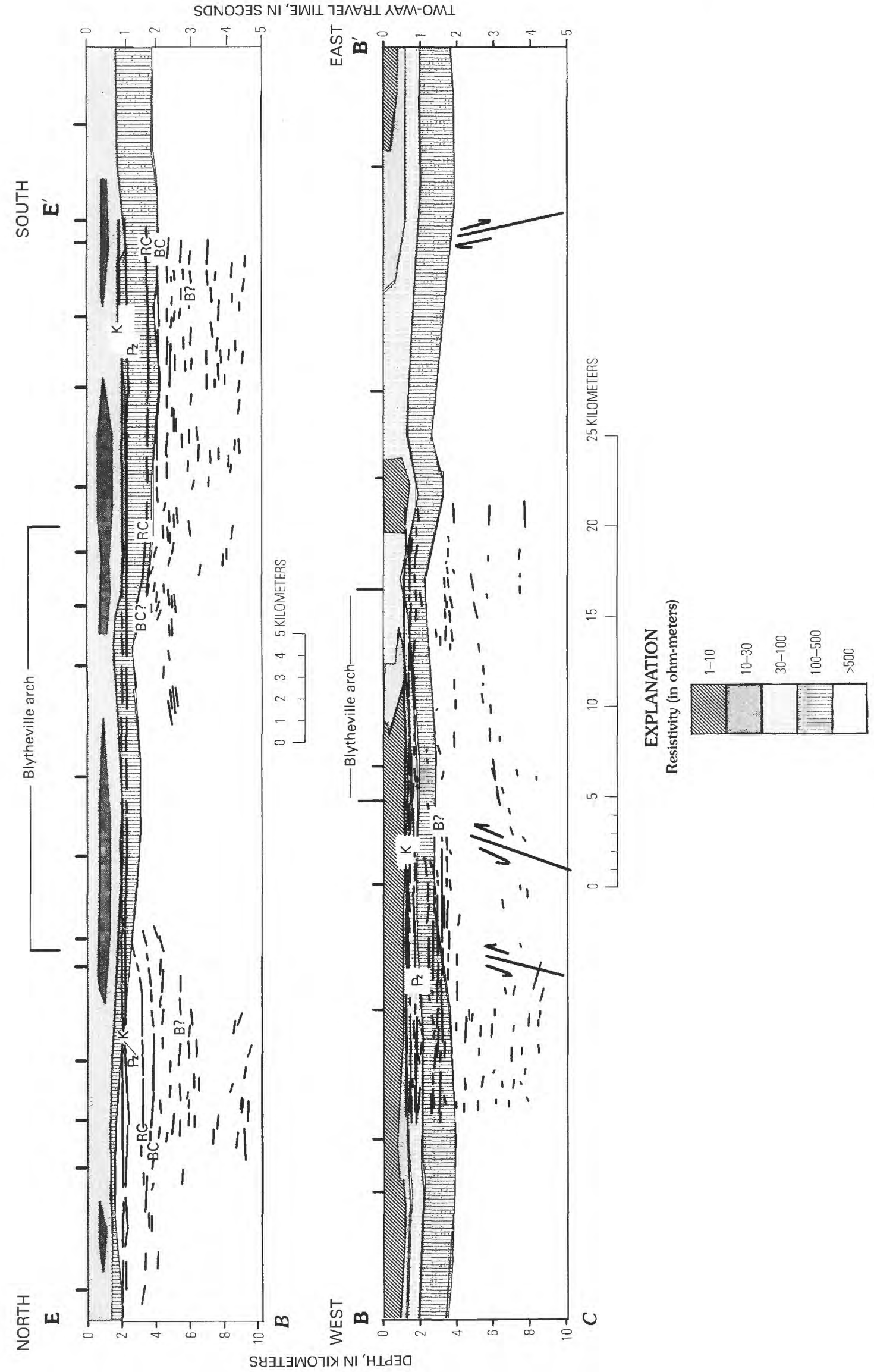


that the pluton covers a larger area than that indicated from figure 1. Thus, the shallower depth to the $>500-\mathrm{ohm}-\mathrm{m}$ units on the eastern end of profiles $C-C^{\prime}$ and $D^{-} D^{\prime}$ may be caused by the pluton and not by the eastern rift boundary. Along profile D-D', the effects of the pluton may mask the expression of the axial structure that appears to have been delineated on MT profiles $A-A^{\prime}, B-B^{\prime}$, and $C_{-} C^{\prime}$ or it may terminate near $\mathrm{D}-\mathrm{D}^{\prime}$. The apparent continuity of an axial structure from $A-A^{\prime}$ to $C-C^{\prime}$ may also be misleading, because an east-west seismic profile $7 \mathrm{~km}$ south of seismic profile 3 (fig. 1) shows very little evidence for the disruption of reflections that typifies the Blytheville arch. In addition, another east-west seismic reflection profile $8 \mathrm{~km}$ south of seismic profile 1 (fig. 1) reveals that, although there is structure with the characteristics of the Blytheville arch, its amplitude is only several hundreds of meters, rather than several kilometers as on other key seismic profiles that were instrumental in discovering the arch. These observations imply that the Blytheville arch and the axial resistivity structure may have considerable amplitude variation along strike and may not be as continuous in character as suggested by the three MT profiles and several seismic reflection profiles. An alternative interpretation for the MT axial structure is one of several uplifts within the axis of the rift, possibly related primarily to intrusions. With all available evidence considered, however, we prefer the interpretation of a continuous axial structure as suggested to us by the MT and seismic reflection data.

\section{SEISMIC REFLECTION AND REFRACTION RESULTS}

The axial structure identified on the MT models was largely unknown prior to this study, although Howe (1984) interpreted an axial-fault system using seismic reflection that was connected with the original version of the Blytheville arch (called "Charlies Ridge" by Howe, 1984). Seismic refraction models (Mooney and others, 1983) from profiles across and along the rift contain a low-velocity zone $(1.8 \mathrm{~km} /$ s) corresponding to the Tertiary and Cretaceous sedimentary rocks and a high-velocity zone with $6.1 \mathrm{~km} / \mathrm{s}$ velocities that represents the Knox-Arbuckle carbonates. The refraction model used a velocity of $4.9 \mathrm{~km} / \mathrm{s}$ for a low-velocity zone interpreted by Mooney and others (1983) to occur beneath the $6.1 \mathrm{~km} / \mathrm{s}$ Knox-Arbuckle carbonates. Neither the thickness nor velocity of this latter low-velocity zone could be determined from the refraction data, but it corresponds to some portion of the Elvins Group, Bonneterre Formation, and basal clastic rocks. It is unlikely that the axial structure interpreted from the MT surveys would have been detected in the refraction travel-time curves because of the effects of this low-velocity zone, which introduces an unresolved layer in the refraction models, and because of the broad spacing of the recording systems in the refraction survey. In a reexamination of the refraction data set, Hamilton and Mooney (1990) interpret that low amplitudes on some of the refraction recording traces are due to attenuation in rocks of the Blytheville arch, rather than to other factors, such as poor coupling of geophones at the surface. They interpret the trace attenuation to be due to (1) defocusing of seismic energy by velocity structures in the arch, and (2) seismic absorption by rocks in the arch. Seismic models have not been developed to simulate the amplitude characteristics of the refraction data; thus, the actual causes of amplitude variability are still poorly understood but could be related to the arch and (or) structures associated with the axial high-resistivity zone.

A line drawing of seismic profile 2 (fig. $8 A$, used by McKeown and others, 1990, in their discussion of the Blytheville arch) shows that the Blytheville arch is defined by the set of warped reflections in the central part of the seismic profile beneath horizontal reflections that were interpreted to mark the top of Cretaceous and Paleozoic rocks. The vertical scaling of the reflection horizons in figure 5 used a velocity of $4 \mathrm{~km} / \mathrm{s}$. In the survey area, the velocity of the upper 0.6- to 1.0-s section (representing Quaternary to Upper Cretaceous units) is about $2 \mathrm{~km} / \mathrm{s}$ and the section from about 1.0 to $2.0 \mathrm{~s}$ (Knox-Arbuckle carbonates and part of Elvins-Bonneterre sequences) has velocities of $4.9-6.1 \mathrm{~km} / \mathrm{s}$ (Andrews and others, 1985); thus, we use a value of $4 \mathrm{~km} / \mathrm{s}$ as an approximate integrated velocity. This conversion allows a qualitative comparison of the MT models and reflection results without requiring a detailed knowledge of the depth-velocity function.

The Blytheville arch appears to be unconformable with the post-Late Paleozoic erosion surface in the reflection records (figs. $8 A, 8 B$ ); thus, the arch must be older than this period. A portion of the MT model for profile E- $E^{\prime}$ (fig. 5) is shown underneath the reflection line drawing (fig. $8 B$ ). The base of the Cretaceous and younger rocks on the MT model corresponds to resistivities of $>30 \mathrm{ohm}-\mathrm{m}$; this boundary agrees well with the reflection data for the depth-conversion velocity used. As discussed above, the top of the Precambrian clastic rocks may coincide with the $>500-\mathrm{ohm}-\mathrm{m}$ zone in the MT models; this is certainly suggested by the correspondence of the reflections picked as basal clastics to the $>500$-ohm-m depth in figure $8 B$.

Another key reflection profile coincides with the central part of MT profile B-B' (seismic profile 3, fig. 1). The Killam No. 1 Pattinson drill hole is located on this seismic profile; the stratigraphy in this well was helpful in interpreting the seismic reflection and MT data. A line drawing of the seismic data from profile 3 (from F.A. McKeown, written commun., 1991) has been superimposed on the coincident portion of MT model B- $\mathrm{B}^{\prime}$ in figure $8 C$. The base of the Cretaceous and younger units again corresponds to $>30 \mathrm{ohm}-\mathrm{m}$ resistivities, and agreement with the reflection data is excellent. The crystalline basement horizon, tentatively picked by F.A. McKeown (written commun., 1991) from the reflection data has much less structure than is indicated on the MT 
model for the western part of the profile. The Blytheville arch disturbed zone occurs on the flank of the axial resistivity high that we interpret to be a horst as denoted by the fault symbols in figure $8 C$.

The reflection line drawings on the full MT models in figure 5 show that the relatively narrow $(10 \mathrm{~km})$ zone of disrupted and arched reflections on the seismic records are located near the center of the much broader $(30-50 \mathrm{~km})$ resistivity axial high on profile B-B' (fig. 5), but on $A-A^{\prime}$ it appears to be displaced toward the west flank of the resistivity structure. The zone of disruption of seismic reflections extends to depths that are apparently greater than the 500 -ohm-m level in the MT models to depths that are or greater than approximate depths to crystalline basement. However, this deeper disruption of reflections may be due to velocity and geometric effects at shallower levels.

\section{RELATIONSHIP TO SEISMICITY}

Seismicity along the northeast trend from Marked Tree to Caruthersville (fig. 1) occurs in near-vertical fault zones at depths of 3-15 km, and focal mechanisms indicate mainly right-lateral slip (Andrews and others, 1985; Chiu and others, 1991). In the northwest-trending seismicity zone through New Madrid, the earthquakes occur at similar depths (Andrews and others, 1985) but along planes that dip $32^{\circ}-55^{\circ} \mathrm{SW}$. that exhibit both normal and thrust motion (Chiu and others, 1991). The general attitude and depth range of these earthquakes is indicated by the asterisks in figure 5 . We interpret that earthquakes in the northeast-trending zone are associated with sets of near-vertical faults bounding and within the axial horst. These seismogenic faults involve both basement rocks and overlying Cambrian to Upper Cretaceous sedimentary rocks; earthquakes may be further concentrated along fault segments that have overpressured conditions (F.A. McKeown and S.F. Diehl, written commun., 1992).

The nature of the axial structure as it approaches the northwest-trending zone of seismicity is unclear. As stated above, it may terminate in the area of MT profile D-D' or, alternately, it may bend to merge with the western rift boundary. The MT strike directions bend from N. $45^{\circ} \mathrm{E}$. to northsouth in the area between sections $C-\mathrm{C}^{\prime}$ and $\mathrm{D}-\mathrm{D}^{\prime}$. This change in direction may be related to the axial pluton noted in figure 1 on the east ends of these profiles. However, highfrequency MT data also indicate a similar change in strike in numerous locations, suggesting that a strong structural grain in the Quaternary sedimentary rocks controls shallow MT strike directions in the region between ${\mathrm{C}-\mathrm{C}^{\prime}}^{\prime}$ and $\mathrm{D}-\mathrm{D}^{\prime}$. This shallow structural grain may be related to sand blows or to faults that extend into the Quaternary fill, but the actual causes of this shallow structural grain is still unclear and their determination will require analysis of detailed, shallow geophysical studies (T.G. Hildenbrand, 1992, oral commun.).

\section{TECTONIC MODEL}

The structural high along the central part of the Reelfoot rift on the MT models (fig. 5) may be similar to axial horsts recognized in numerous aulacogens (Milanovsky, 1981). The formation of these axial horsts is related to a process called "inversion" by Milanovsky (1981); this process of intra-rift horst development may be related to a combination of post-rift intrusions, regional compression, or isostatic response to thick depocenters along the axial zones. The inversion process is commonly repeated several times during an aulacogen's long geological history (Milanovsky, 1981), leading to complex sets of faults within and bounding the axial uplifts.

As depicted in figure 9, the early stages of the Reelfoot rift included deposition of thick basal clastic rocks (fig. 9), sometimes referred to as the Lamotte Sandstone (Howe, 1984). In late Cambrian time, a thick sequence of anoxic shales in the Elvins Group and carbonates of the Bonneterre Formation were deposited (fig. 9). We show the axial horst as developing during this period. Strong variations in resistivity of the Elvins Group in the Garrigan well and complexity of the electrical signatures of the Bonneterre Formation in the Wilson well suggests rapid facies changes that may have been related to formation of the proposed horst. We interpret that the horst may have subdivided the rift into two, deep, shale basins in Middle to Late Cambrian time, with a carbonate platform developing over the horst axis. Regional downwarping in Late Cambrian to Middle Ordovician time led to deposition of the thick Arbuckle-Knox carbonates, possibly initiating an episode of overpressuring documented by Diehl and McKeown (1991). Uplift that began in late Paleozoic and possibly continuing into Mesozoic time led to partial erosion of the Arbuckle-Knox carbonates and preservation of the arch structure delineated in the seismic reflection data of figure 8. Intrusions were localized along some rift structures, possibly including the axial horst, in the Permian and in Cretaceous time (F.A. McKeown, oral commun., 1992). Subsidence of the region surrounding the rift during Late Cretaceous led to deposition of Upper Cretaceous to Lower Tertiary units of the Mississippi Embayment (fig. 9). Faults are interpreted to occur in higher concentrations along the axial horst and, as in other inversion structures within rifts worldwide (Milanovsky, 1981), many of the faults are thrust faults. Overpressuring of the thick Elvins shale may have continued to the present time, as suggested by Diehl and McKeown (1991) and may be a selective factor in determining which of the axial faults associated with the proposed horst actually generate earthquakes.

The Blytheville arch has been interpreted as a diapiric structure caused by gravitationally unstable (lower density) sedimentary rocks rising upward into higher density rocks (McKeown and others, 1990). In addition, it has been suggested that overpressured fluids have played a role in formation of the arch (Diehl and McKeown, 1991). The seismic 

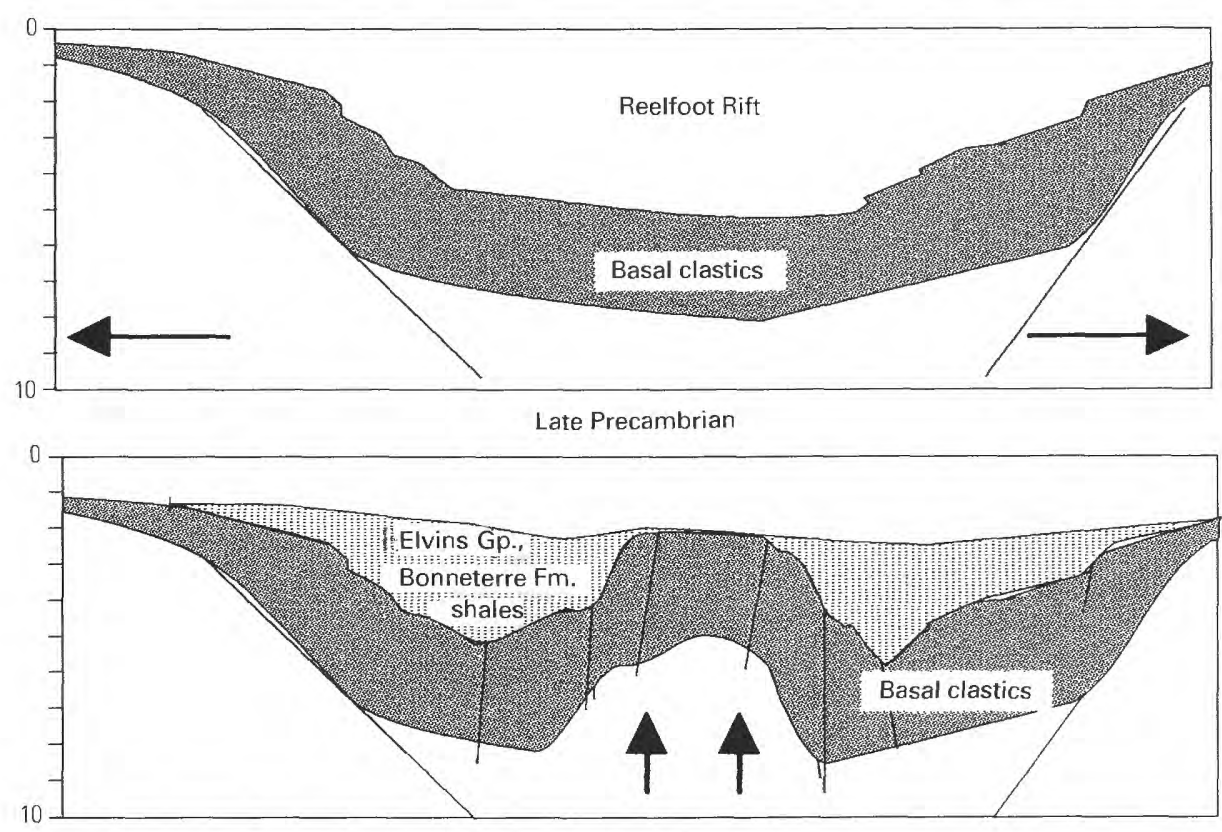

Early Cambrian

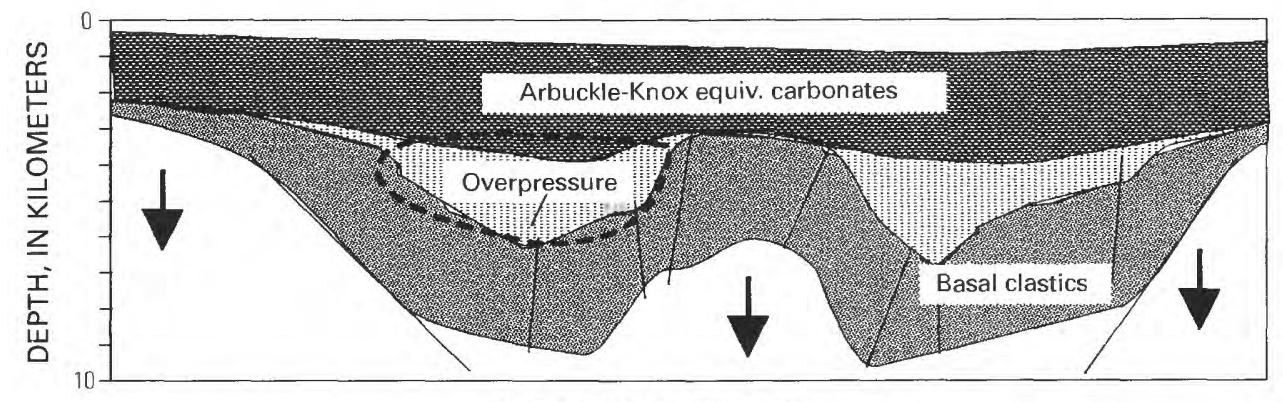

Late Cambrian to Middle Ordovician
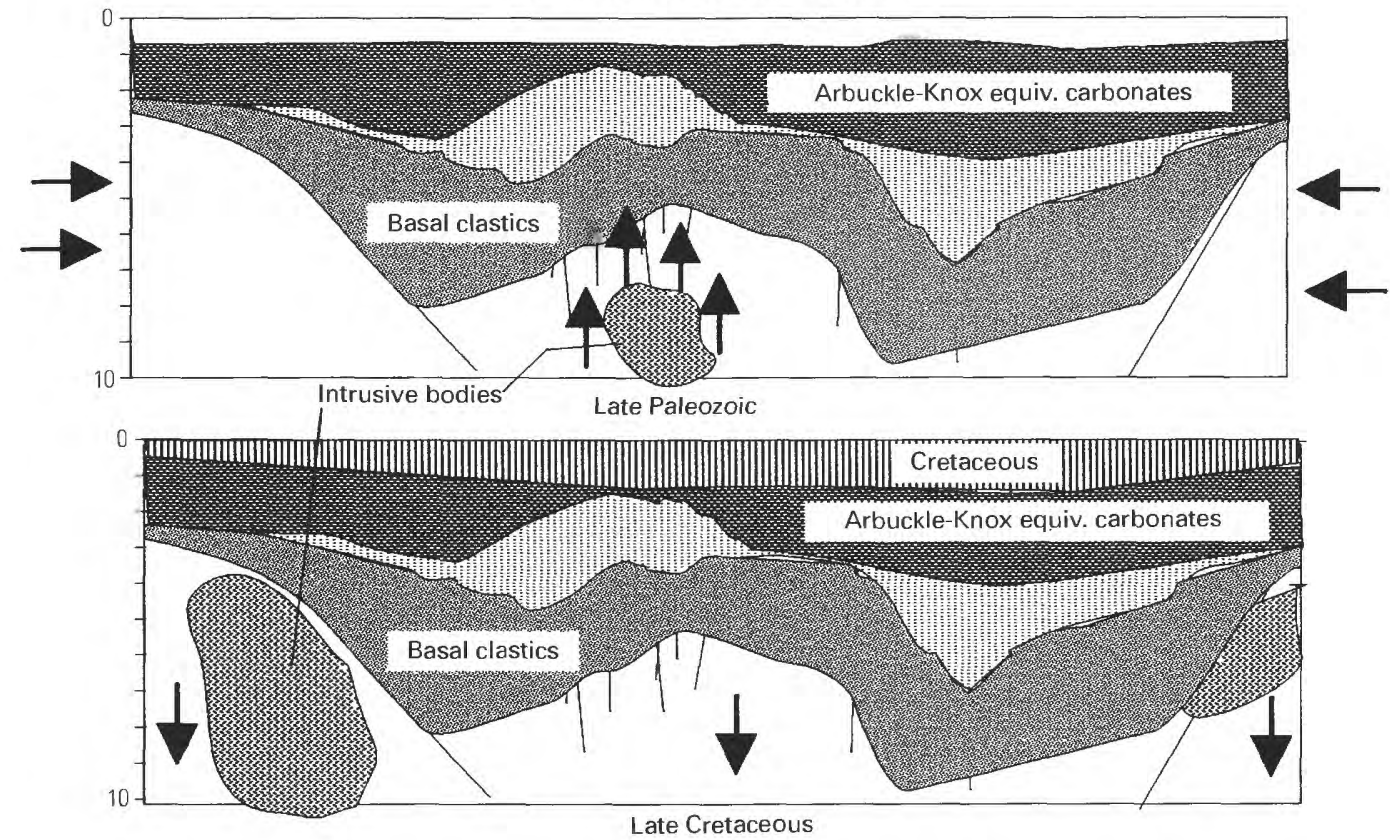

Figure 9. Tectonic reconstruction of development of a proposed axial horst in the Reelfoot rift. Arrows represent direction of crustal motions. 


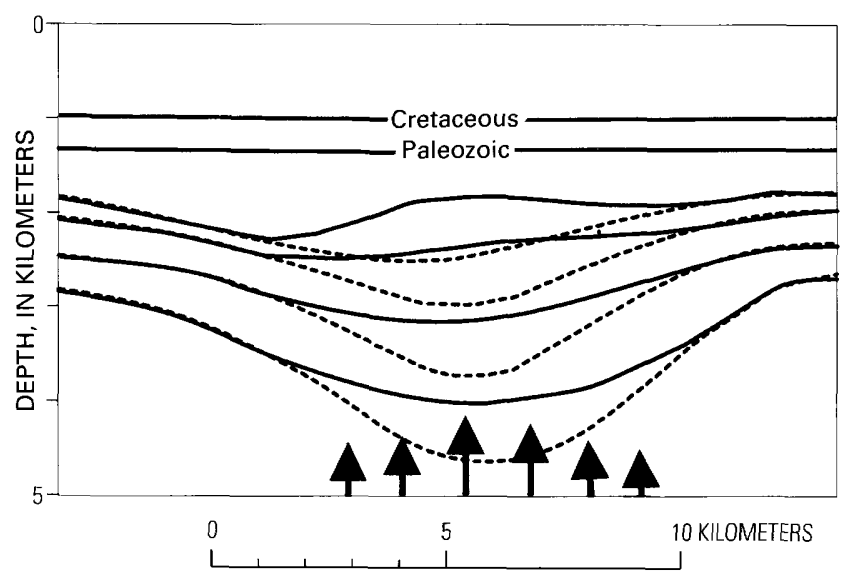

Figure 10. Drawing showing possible upwarping of reflection horizons by simple uplift (arrows) rather than diapiric or intrusive processes. Dotted lines are original horizons. Solid lines show final position of horizons after uplift.

reflection features used to define the arch may simply be related to differential uplift on faults that the axial structure mapped in the MT surveys. It is possible to produce upwarped reflections from a layered sequence by invoking differential uplift over a horizontal distance approximately equal to the scale length of the anomalous feature. This is illustrated in figure 10, where an original sequence of sedimentary layers (shown by the dotted lines) has been uplifted by a bell-shaped uplift vector (arrows in the lower part of figure). The resultant interfaces suggest internal "pillowing" that might be attributed to intrusive activity or diapirism, but are only the result of differential uplift on beds of varying thickness. In addition, if a bell-shaped high velocity occurred over the region of distorted reflectors, then the distortion of arrival times for reflectors could mimic the patterns of observed reflections. For this latter exercise, the bell-shaped uplift vector in figure 10 could be replaced by a bell-shaped positive velocity anomaly occurring near the Paleozoic boundary. Shales are generally lower velocity than carbonate rocks, so the latter possibility is probably not realistic in terms of any proposed models and well evidence.

The divergence of reflector dips in the seismic reflection drawing of figure 8 have been cited (A.J. Crone, written commun., 1992) as evidence for intrusion of material between crystalline rocks below and sedimentary rocks above. However, the uplift model of figure 10 can clearly cause divergence in reflection horizons, as shown by the solid lines indicating the final state of the rocks in this model. To have "introduction of material between the crystalline basement and overlying sedimentary rocks," one would expect to have had diapirism involving units such as shale or, alternately, igneous activity. It is clear from study of aeromagnetic data (in Hildenbrand, 1985) that there is no linear magnetic anomaly that might be expected from a linear zone of intrusions at the depths of the arched reflections; thus, it is not likely that igneous activity is the cause of the arched reflections. Release of high pore pressures in the thick Elvins shales in the area of the Blytheville arch upon erosion of the overlying Knox-Arbuckle rocks (fig. 9) may have caused volume expansion of these shales and formation of the arch. This would have required local thinning of the compressing medium (made up of the Knox-Arbuckle rocks over the axis of the arch), which would have required localized uplift. If this localized uplift did occur, then both the release of fluid pressures and the effect of differential uplift indicated in figure 10 may have contributed to the appearance of reflection horizons in figure 8. The Elvins Group shale rocks have relatively high densities of $>2.7 \mathrm{gm} / \mathrm{cm}^{3}$ (T.G. Hildenbrand, oral commun., 1992), and significant volume expansion in the area of the Blytheville arch should give rise to a linear gravity low. Such a linear gravity low has not been detected as yet; in fact, recently compiled residual gravity maps indicate a linear gravity high that appears to coincide with the Blytheville arch (V. Langenheim and T.G.' Hildenbrand, written commun., 1992). This gravity high also is negative evidence for diapirism involving lower density shales intruding higher density rocks above.

In summary, four factors may have led to formation of the arch: (1) igneous intrusions, (2) diapirism involving lowdensity shales, (3) volume expansion due to release of highpore-pressure fluids, and (4) vertical uplift of formations with varying thickness. Because of the absence of linear magnetic anomalies, explanation (1) must be discounted; because of the existence of a linear gravity high over the arch (2) and (3) must be somewhat discounted. Because the Elvins Group shales are so dense $\left(2.7 \mathrm{gm} / \mathrm{cm}^{3}\right)$, vertical uplift of these shales as in explanation (4) and represented in figure 10 would give a linear gravity high. However, the Blytheville arch is related to quite complex stress and geological factors that we only attempt to categorize, and we do not claim to have narrowly constrained its origin.

\section{SUMMARY AND CONCLUSIONS}

We have described the results of the first MT surveys done in the Reelfoot rift region. The data was interpreted with two-dimensional models to show details of structure within the rift such as the high-resistivity structure that may represent an axial horst. Comparison of seismic reflection data with the MT models shows that the Blytheville arch is a considerably more narrow structure than the axial, high-resistivity structure, and we interpret that the Blytheville arch may be related to differential uplift on faults that flank the axial horst. These flanking faults may be responsible for localizing seismicity in the northeast-trending zone of seismicity from Marked Tree, Ark., to Caruthersville, Mo. The margins of the rift-fill sedimentary sequences were well defined by the MT models, but because of the large effect of these conductive sedimentary sequences, we were unable to detect any subupper-crustal structures of the rift (such as the "rift-pillow" 
interpreted from seismic refraction models). With the present data set, we were only able to establish that deep crustal ( $>10$ $\mathrm{km}$ ) resistivities must be greater than $100 \mathrm{ohm}-\mathrm{m}$, ruling out the possibility of large magma chambers or pervasive deep crustal fluids. Actual depth to crystalline basement in the main part of the rift is poorly resolved due to the high resistivity in the lower part of the rift fill and the low resistivities of the overlying Mississippi Embayment sequences. Intrusive bodies along the margins of the rift that have been mapped with aeromagnetic data were not detected in the MT surveys, largely because the intrusive rocks have resistivities close to those of the Precambrian gneisses that form the basement. Although the MT method has much poorer resolution with depth than seismic reflection techniques, the combination of the two geophysical tools provides a refined view of the subsurface in the Reelfoot rift region.

\section{ACKNOWLEDGMENTS}

The authors wish to thank Frank McKeown, Tom Hildenbrand, and Anthony Crone. for providing extremely useful reviews of the manuscript and much of the insight, as well as geologic and seismic data, that we needed to understand the setting of the Reelfoot rift. We are especially indebted to Torquil Smith and John Booker, University of Washington, for providing their code for the RRI algorithm which allowed us to efficiently interpret the large set of MT data. Their software represents a major advance in the field of MT interpretation. This research was done under auspices of the U.S. Geological Survey National Earthquake Hazards Reduction Program.

\section{REFERENCES CITED}

Acuna, M.H., Searce, C.S., Seek, J.B., and Scheifele, J., 1973, The MAGSAT vector magnetometer-A precision fluxgate magnetometer for the measurement of the geomagnetic field: Greenbelt, Md., NASA Goddard Space Flight Center, Technical Memorandum No. 79656, 18 p.

Andrews, M.C., Mooney, W.D., and Meyer, R.P., 1985, The relocation of microearthquakes in the northern Mississippi Embayment: Journal of Geophysical Research, v. 90, p. 10223-10236.

Bendat, J.S., and Piersol, A.G., 1971, Random Data: Analysis and Measurement Procedures: New York, Wiley Interscience. $407 \mathrm{p}$.

Booker, J.R., 1991, Removal of static distortion from 2-D inversions of MT data [abs.]: American Geophysical Union Fall Meeting, Program and Abstracts, p. 129.

Chiu, J.M., Yang, Y.T., Chen, K.C., Liaw, Z.S., Chiu, S.C., Johnston, A.C., and the PANDA Group, 1991, 3-dimensional fault zone geometry and sedimentary basin configuration in the central New Madrid seismic zone determined from PANDA array data [abs.]: Memphis, Tenn., Proceedings of the Eastern
Section of the Seismological Society of America, 63rd Annual Meeting, p. 44.

Clarke, J., Gamble, T.D., Goubau, W.M., Koch, R.H., and Miracky, R.F., 1983, Remote-reference magnetotellurics: Equipment and procedures: Geophysical Prospecting, v. 31, p. 149-170.

Collins, D.S., Taylor, M.E., Repetski, J.E., and Palmer, A.R., 1992 , New sedimentologic and paleontologic data for the Dow Chemical No. 1 B.L. Garrigan drill hole, Mississippi County, Arkansas: U.S. Geological Survey Open-File Report 92-6, 38 p.

Diehl, S.F., and McKeown, F.A., 1991, Evidence of paleo- and recent fluid overpressure in the New Madrid seismic zone of the Reelfoot rift, southeast and northeast Arkansas [abs.]: Memphis, Tenn., Proceedings of the Eastern Section of the Seismological Society of America, 63rd Annual Meeting, p. 68.

Dobrin, M.B., and Savit, C.H., 1988, Introduction to Geophysical Prospecting (4th ed.): New York, McGraw-Hill, 867 p.

Ervin, C.P., and McGinnis, L.D., 1975, Reelfoot rift-A reactivated precursor to the Mississippi Embayment: Geological Society of America Bulletin. v. 86, p. 1287-1295.

Gamble, T.D., Goubau, W.M., and Clarke, John, 1979, Magnetotellurics with a remote reference: Geophysics, v. 44, p. 53-68.

Hamilton, R.M., and Johnston, A.C., 1990, Tecumseh's prophecy: Preparing for the next New Madrid earthquake: U.S. Geological Survey Circular 1066, $30 \mathrm{p}$.

Hamilton, R.M., and McKeown, F.A., 1988, Structure of the Blytheville arch in the New Madrid seismic zone: Seismological Research Letters, v. 59, no. 4, p. 117-121.

Hamilton, R.M., and Mooney, W.D., 1990, Attenuation of seismic waves in the upper crust of the New Madrid seismic zone: Science, v. 248, p. 351-354.

Hildenbrand, T.G., 1985, Rift structure of the northern Mississippi Embayment from the analysis of gravity and magnetic data: Journal of Geophysical Research, v. 90, p. 12607-12622.

Howe, J.R., 1984, Tectonics, sedimentation, and hydrocarbon potential of the Reelfoot aulacogen: University of Oklahoma, unpub. M.S. thesis, $75 \mathrm{p}$.

Illies, J.H., 1981, Mechanism of Graben Formation: Amsterdam, Elsevier Scientific Publishing Company, 266 p.

McKeown, F.A., Hamilton, R.M., Diehl, S.F., and Glick, E.E., 1990, Diapiric origin of the Blytheville and Pascola arches in the Reelfoot rift, East-Central United States: Relation to New Madrid seismicity: Geology, v. 18, p. 1158-1162.

Milanovsky, E.E., 1981, Aulacogens of ancient platforms: Problems of their origin and tectonic development: Tectonophysics, v. 73, p. 213-248.

Mooney, W.D., Andrews, M.C., Ginzburg, A., Peters, D.A., and Hamilton, R.M., 1983, Crustal structure of the northern Mississippi Embayment and a comparison with other continental rift zones: Tectonophysics, v. 94, p. 327-348.

Nuttli. O.W., 1973, The Mississippi valley earthquakes of 1811 and 1812-Intensities, ground motion and magnitudes: Bulletin of the Seismological Society America, v. 63, p. 227-248.

Olhoeft, G.R., 1981, Electrical properties of granite with implications for the lower crust: Journal of Geophysical Research, v. 86, p. 931-936.

Smith, J.T., and Booker, J.R., 1988, Magnetotelluric inversion for minimum structure: Geophysics, v. 53, p. 1565-1576.

1991. Rapid inversion of two- and three-dimensional magnetotelluric data: Journal of Geophysical Research, v. 96, p. 3905-3922. 
Stanley, W.D., Mooney, W.D., and Fuis, G.S., I990, Deep crustal structure of the Cascade Range and surrounding region from seismic refraction and magnetotelluric data: Journal of Geophysical Research, v. 95, no. B12, p. 19419-19438.

Stanley, W.D., and Tinkler, R.D., 1983, A practical, low-noise coil system for magnetotellurics: U.S. Geological Survey OpenFile Report 83-85, 18 p.

Published in the Central Region, Denver, Colorado Manuscript approved for publication November 9, 1994 Edited by Richard W. Scott, Jr.

Graphics prepared by Norma J. Maes; use made of author-drafted material

Photocomposition by Mari L. Kauffmann
Sternberg, B.K., Washburne, J.C., and Pellerin, L., 1988, Correction for the static shift in magnetotellurics using transient electromagnetic soundings: Geophysics, v. 53, p. 1459-1468.

Thomas, W.A., 1991, The Appalachian-Ouachita rifted margin of southeastern North America: Geological Society of America Bulletin, v. 103, p. 415-431.

Vozoff, Keeva, 1972, The magnetotelluric method in the exploration of sedimentary basins: Geophysics, v. 37, p. 98-141. 


\section{APPENDIX A \\ MAGNETOTELLURIC METHOD}

MT data consist of measurements of the orthogonal components of time-varying surface magnetic fields and their associated electric fields. These fields occur naturally as a result of electromagnetic induction in the Earth from magnetic variations originating in the ionosphere and atmosphere. In our surveys, horizontal electric fields were sensed using an L-shaped, three-electrode array with dipole lengths of $37.5 \mathrm{~m}$. The orthogonal, horizontal magnetic fields in the direction of the electric-field-measurement array were sensed using permalloy-cored induction coils (Stanley and Tinkler, 1983). The vertical magnetic field was measured only at selected sounding sites when a ring-core fluxgate magnetometer (Acuna and others, 1973) was deployed for magnetic-field sampling instead of the induction coils. Time-series recordings of the electrical- and magnetic-field data were acquired using a computer-controlled data-acquisition system, with the computer and other electronics powered by marine storage batteries. The acquisition system used an analog signal-conditioning system for pre-whitening of the input spectrum and post-amplification, combined with a 12-bit analog-to-digital converter. Data were recorded to disk for pass-bands at the three frequency ranges of $0.002-0.2 \mathrm{~Hz}, 0.05-3 \mathrm{~Hz}$, and $2-300 \mathrm{~Hz}$. The measurements spanned a period of about 2-3 hours and included three to six recordings of the higher frequency bands and one to four recordings of the lowest frequency band. At selected sounding sites, the ring-core fluxgate magnetometer was used instead of the induction coils for magnetic-field measurement to obtain vertical magnetic-field data and to extend the MT data to frequencies of $0.0002 \mathrm{~Hz}$ (one decade lower than that obtainable with the three standard bands above). An automated, battery-powered data-acquisition system designed by V.F. Labson (written commun., 1989) was used with the ring-core-magnetometer system and associated electric-field sensors (identical to those used for the three standard bands). The automated system was deployed for at least 9 hours to record the lower frequency data.

The time-series data were converted to complex crossspectra using FFT (fast-Fourier-transform) techniques. Least-squares, cross-spectral analysis (Bendat and Piersol, 1971) were used to solve for a tensor-transfer function relating the observed electric fields to the magnetic fields under the assumption that the Earth consists of a two-input, twooutput, linear system with the magnetic fields as input and the electric fields as outputs:

$$
Z_{i j}=E_{i}+H_{j}
$$

where

$$
Z_{i j} \text { is the impedance tensor, }
$$

$E_{i}$ are the two horizontal electric fields,

$H_{j}$ are the two horizontal magnetic fields, and

all quantities are a function of frequency.

When the vertical magnetic field was measured, the vertical-field-transfer function (or "tipper") was solved for, with the assumption that the vertical field is the output of a two-input, one-output system (with the vertical field as the output):

$$
H_{z}=A H_{x}+B H_{y}
$$

where

$H_{x}$ and $H_{y}$ are the horizontal magnetic fields,

$H_{Z}$ is the vertical magnetic field, and

$A$ and $B$ are the transfer-function elements.

The impedance tensor, $Z_{i j}$, is treated as amplitude and phase quantities. The amplitude of the tensor is converted to "apparent resistivities" using the relationship between the resistivity of a homogeneous Earth to the tensor-impedance relationship between surface electric and magnetic fields:

$$
\rho_{a}=\frac{1}{\omega \mu_{0}}\left[\frac{E_{i}}{H_{j}}\right]^{2}
$$

where

$\rho_{a}$ is the "apparent resistivity,"

$E_{i}$ and $H_{j}$ are the orthogonal electric- and magnetic-field pairs,

$\omega$ is the radian frequency, and

$\mu_{0}$ is the magnetic permeability (assumed to be the same as free space at MT frequencies).

The phase of the impedance tensor, $\phi$, is given by the arctangent of the amplitude of the real part of the tensor to the imaginary part:

$$
\phi=\arctan \left(Z_{\text {real }} / Z_{\text {imaginary }}\right)
$$

The measured resistivity and phase values are plotted versus frequency for computer modeling. Both the resistivity and phase data are normally used in the modeling, although it can be demonstrated that they are not independent by means of the Hilbert transform (Bendat and Piersol, 1971). Prior to conversion to resistivity and phase, the tensor is normally rotated into principal directions that usually correspond to the direction of maximum and minimum resistivity. For a two-dimensional (2-D) Earth, the MT fields can be decoupled into transverse electric (TE) and transverse magnetic (TM) modes; two-dimensional modeling is generally done to fit both modes. When the geology satisfies the 2-D assumption, the MT data for the TE mode is assumed to represent the situation when the electric field is along the geologic strike, and the data for the TM mode is assumed to represent the situation when the electric field is across strike. 
A measure of the correctness of the 2-D assumption for MT data is provided by the skew of the impedance tensor, defined as the ratio of the magnitude of the diagonal elements over the off-diagonal elements (Vozoff, 1972). If the geology is truly 2-D, then the skew will be zero. Remote or local reference sensors can be used to help reduce bias in the impedance determinations due to instrument or environmental noise (Gamble and others, 1979; Clarke and others, 1983). Although reference techniques were not used in our survey, we did sort cross-power files to select optimal signalto-noise data sets.

Man-made electrical noise, such as power lines and irrigation pumps, can have a negative effect on MT data quality. In the survey area, there are numerous small power lines that did not affect data quality as long as the soundings were done about $0.4 \mathrm{~km}$ from them. Large sprinkler systems driven by electric irrigation pumps were more of a problem and were not approached closer than $1.5 \mathrm{~km}$ for soundings. Local lightning, wind, and rainstorms can also degrade data quality, but these can be generally avoided by planning surveys to miss the most active thunderstorm periods. The MT signals that originate in the ionosphere and from equatorial lightning belts vary in spectral densities (amplitudes) from several factors. The lower frequency ionospheric signals $(0.0001$ to $1 \mathrm{~Hz})$ are related to sunspot activity, and the last 3 years have been ones of high sunspot activity and good signal levels, but, even in low sunspot activity, the MT signals are adequate for year-round MT surveys. Higher frequency MT signals (1 Hz to $10,000 \mathrm{~Hz}$ ) that are generated largely from equatorial lightning storms that propagate in the Earthionospheric waveguide have minimums in amplitude in the Northern Hemisphere winter; this amplitude minimum does cause problems with some wintertime MT surveys using the higher frequency ranges. An excellent introduction to the MT method and references for a more advanced understanding are contained in Dobrin and Savit (1988).

\section{INTERPRETATION OF MT AND SEISMIC DATA}

Resistivities in rocks are largely controlled by ionic conduction in pore fluids and clay minerals in rocks, rather than by electronic conduction through the rock-matrix resistivity itself. Archie's law (Olhoeft, 1981) expresses a relationship between pore-fluid resistivity, rock-matrix resistivity, and actual rock resistivity.

$$
\rho_{r}=\mathrm{A} \rho_{\mathrm{w}} \Phi^{-\mathrm{m}}
$$

where

$\rho_{r}$ is bulk resistivity of the rock with a water resistivity of $\rho_{u^{\prime}}$ and a porosity of $\Phi$ (raised to the empirical value

$$
-\mathrm{m}) \text {, and }
$$

$\mathrm{A}$ is an empirical constant.

The constant, A, varies from slightly less than 1 with rocks having mainly intergranular porosity to slightly more than 1 for rocks with mainly joint porosity. The exponent, $\mathrm{m}$, is somewhat larger than 2 for cemented and well-sorted granular rocks and less than 2 for poorly sorted and poorly cemented granular rocks.

Resistivities in most rock-forming minerals are quite high, typically greater than $1,000 \mathrm{ohm}-\mathrm{m}$, but typical values for basin-filling sedimentary rocks or marine sedimentary rocks are low (1-100 ohm-m) due to the low resistivity of pore fluid. As porous rocks are buried deeper than a few kilometers, porosities are decreased due to lithostatic loading until the rocks normally become highly resistive. In shales, ionic conduction also occurs in water trapped in clays and zeolites; as a result, the resistivity of shales will be low (1-20 ohm-m) and vary less than other lithologies as porosity decreases. As shales are metamorphosed, both porosity and layered clays are destroyed, but low resistivities can still be maintained due to the formation of carbonaceous or iron mineral films along bedding planes in the metashales. Intrusive rocks have minor porosity and, thus, are normally very resistive, typically in the range of 500-20,000 ohm-m. Fracture porosity and intense alteration of intrusive rocks can lower their resistivity well below this range. Unaltered volcanic rocks have very high resistivities when pore waters are fresh; however, as volcanic rocks increase in age, the formation of clays and zeolites dramatically decreases their resistivity. In our MT surveys of the Reelfoot rift, the variety of rocks and physical conditions mean that resistivities were expected to vary from 1 to $10,000 \mathrm{ohm}-\mathrm{m}$, with conductive shales at the low end of the spectrum and crystalline rocks at the high end.

Seismic compressional-wave velocities for rocks in the Reelfoot rift vary from about 1.8 to greater than $6 \mathrm{~km} / \mathrm{s}$, as determined from well logs and seismic refraction surveys (Mooney and others, 1983). The lowest velocities are in Cenozoic and Cretaceous sedimentary rocks. High-dolomite-content carbonate rocks of the Knox or Arbuckle Group equivalents have velocities of about $6.1 \mathrm{~km} / \mathrm{s}$, and Elvins Group shale and Bonneterre Formation carbonate rocks beneath the Knox-Arbuckle Group equivalents have velocities of $4.9-5.5 \mathrm{~km} / \mathrm{s}$. The velocity of intrusive rocks is influenced by the proportion of quartz to mafic minerals in the rocks, with felsic rocks such as granite having velocities of about $5-6 \mathrm{~km} / \mathrm{s}$ and intermediate to mafic intrusive rocks ranging higher than $6.3 \mathrm{~km} / \mathrm{s}$. The recording of reflections from geologic formations is dependent upon sufficient acoustic contrast and favorable geometry of the reflecting surfaces. Because of the different controls over resistivity and compressional velocities, we do not expect complete agreement between MT and seismic interpretation. 


\section{APPENDIX B}

The following pages show plots of the observed data input to the 2-D inversion program and the computed data for the derived model for each individual sounding on the five magnetotelluric (MT) profiles shown in figure 5. The station numbers for profiles A-A', B-B', C-C', and D-D' represent, with increasing numbers, positions along the profile from west to east. Increasing station numbers on profile $E-E^{\prime}$ represent positions along the profile from north to south. On the plots, $x$ 's indicate the digitized values of the transverseelectric (TE) resistivity data from the MT soundings after hand-smoothing of the curves. Solid lines represent computed TE data for the models shown in figure 5. The plots are arranged by profile (A-A', B-B'. C-C', D-D', and E-E'), and, for each profile, resistivity plots are followed by phase plots.
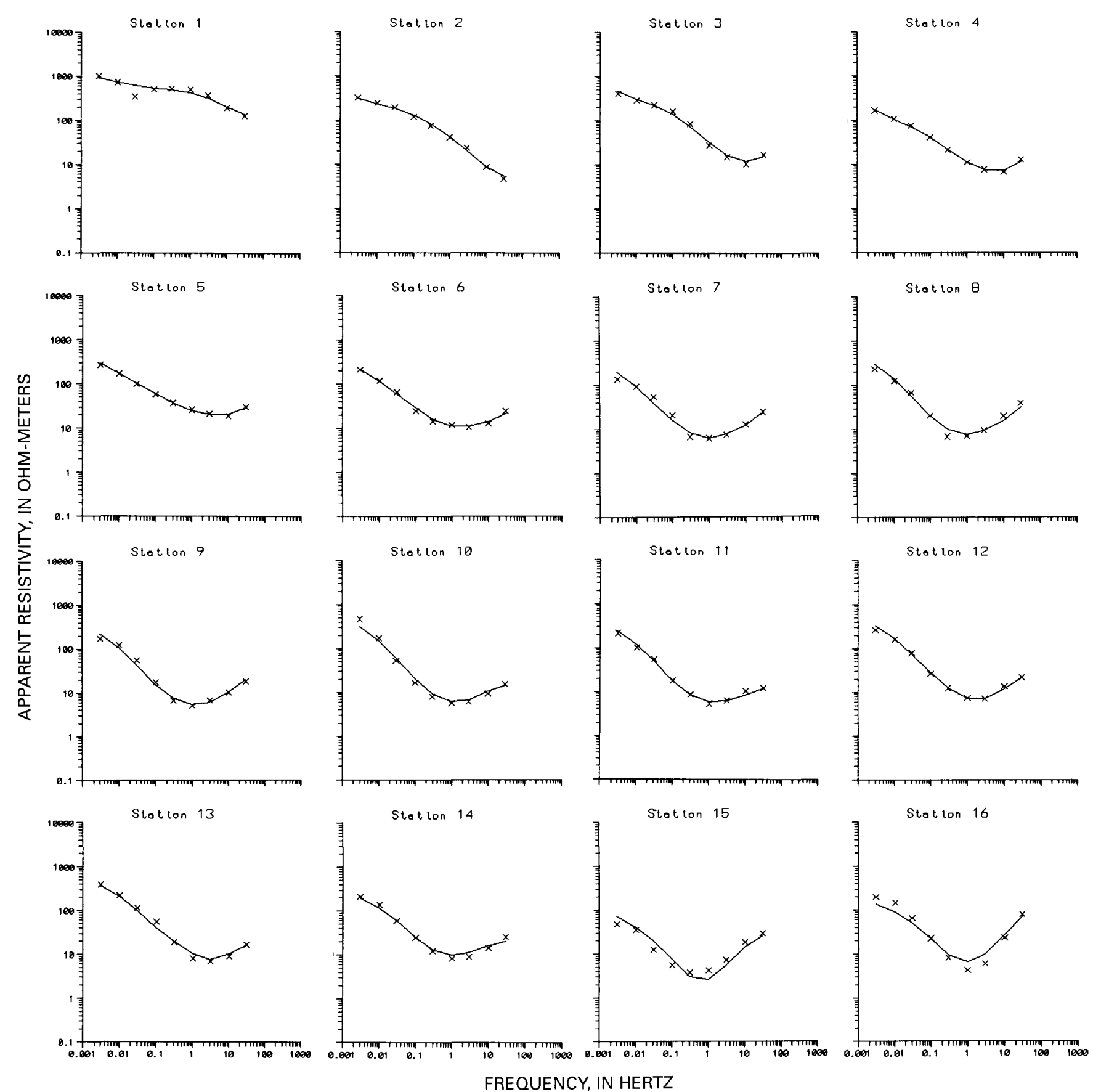

Figure B1 (above and facing page). Resistivity plots for 23 stations along profile A-A' (see fig. 5). See Appendix A for explanation of "apparent resistivity." Increasing station numbers represent positions along the profile from west to east. 

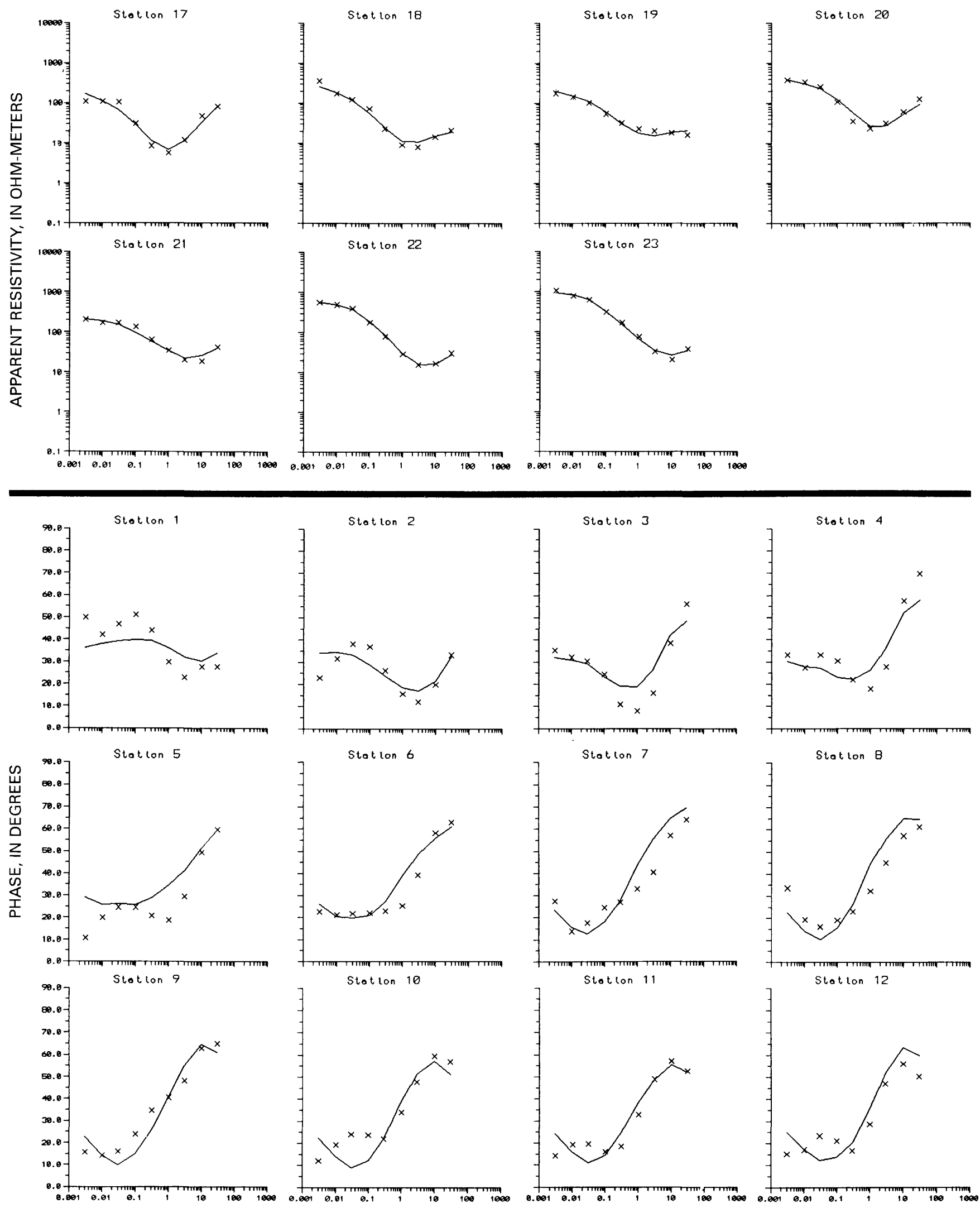

FREQUENCY, IN HERTZ

Figure B2 (above and following page). Phase plots for 23 stations along profile A- $\mathrm{A}^{\prime}$ (see fig. 5). Increasing station numbers represent positions along the profile from west to east. 

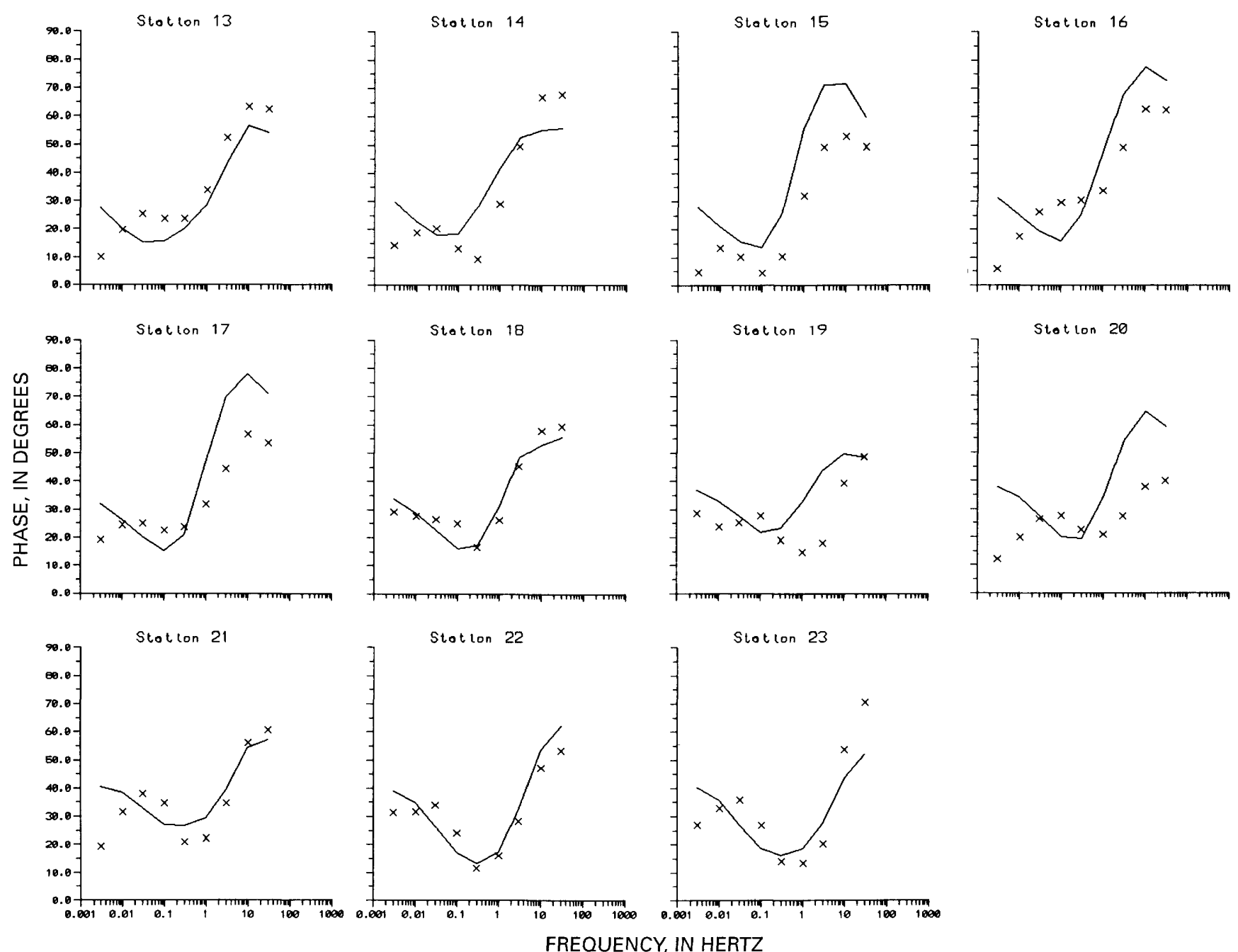

FREQUENCY, IN HERTZ 

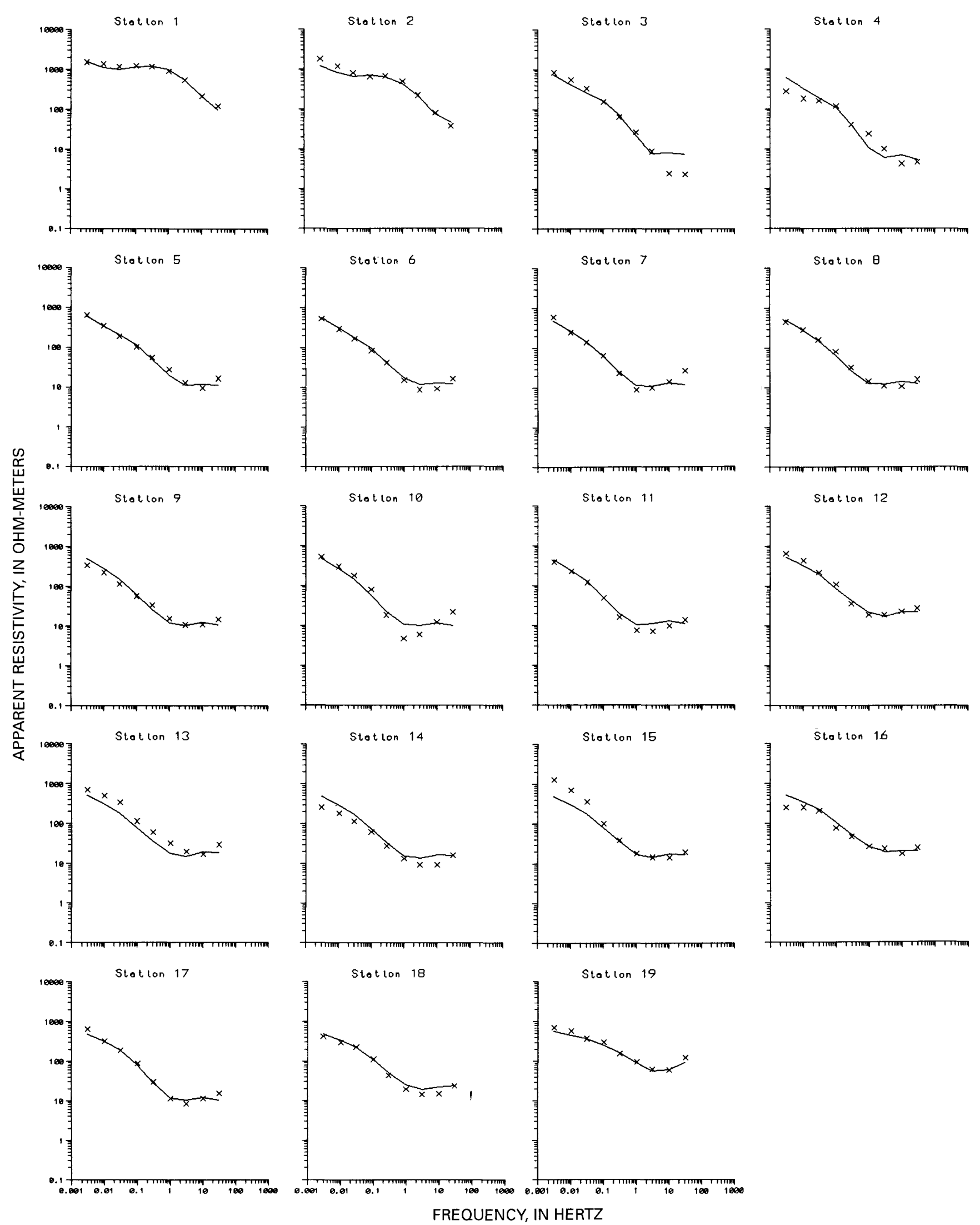

Figure B3. Resistivity plots for 19 stations along profile B-B' (see fig. 5). See Appendix A for explanation of "apparent resistivity." Increasing station numbers represent positions along the profile from west to east. 

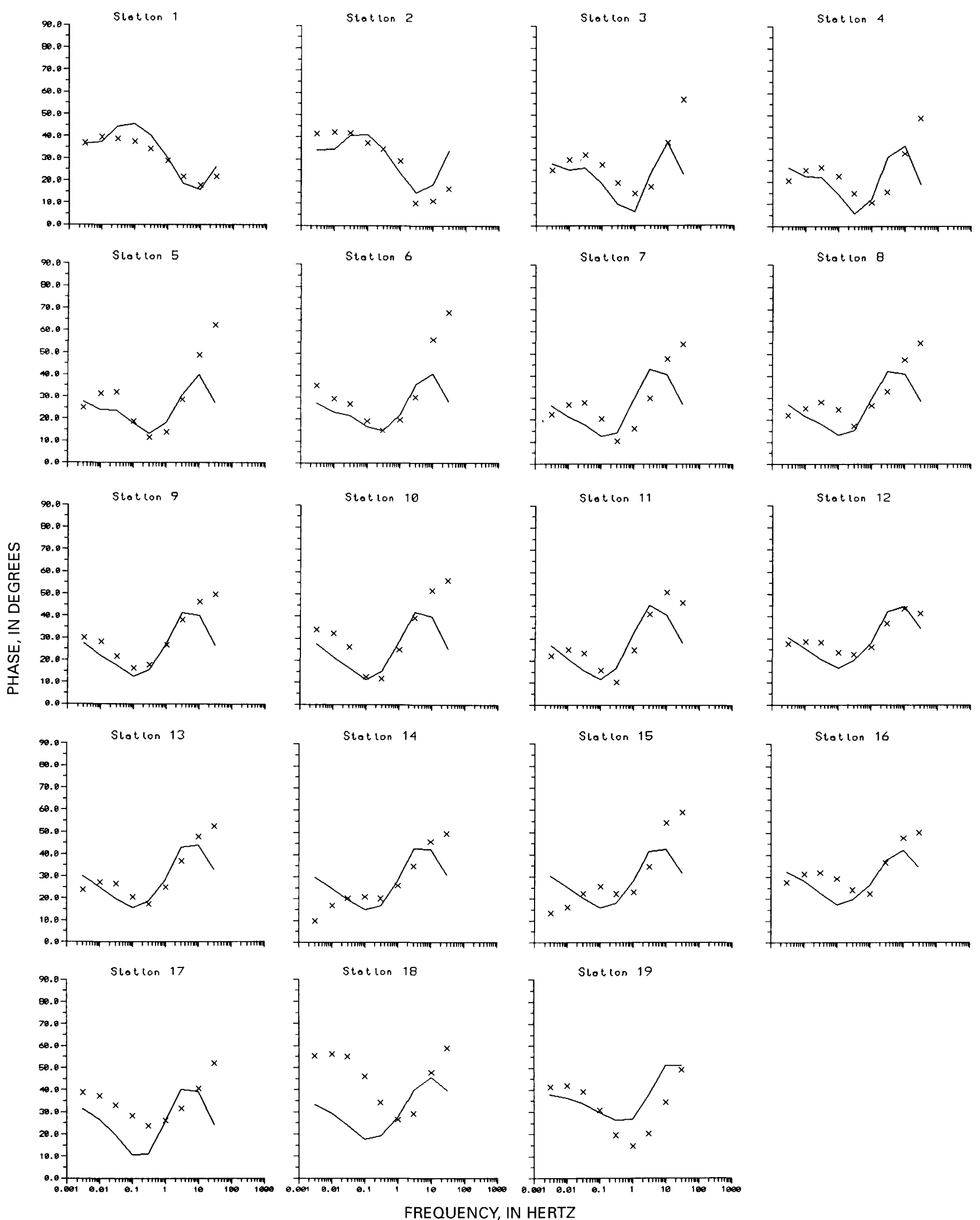

Figure B4. Phase plots for 19 stations along profile B-B' (see fig. 5). Increasing station numbers represent positions along the profile from west to east. 

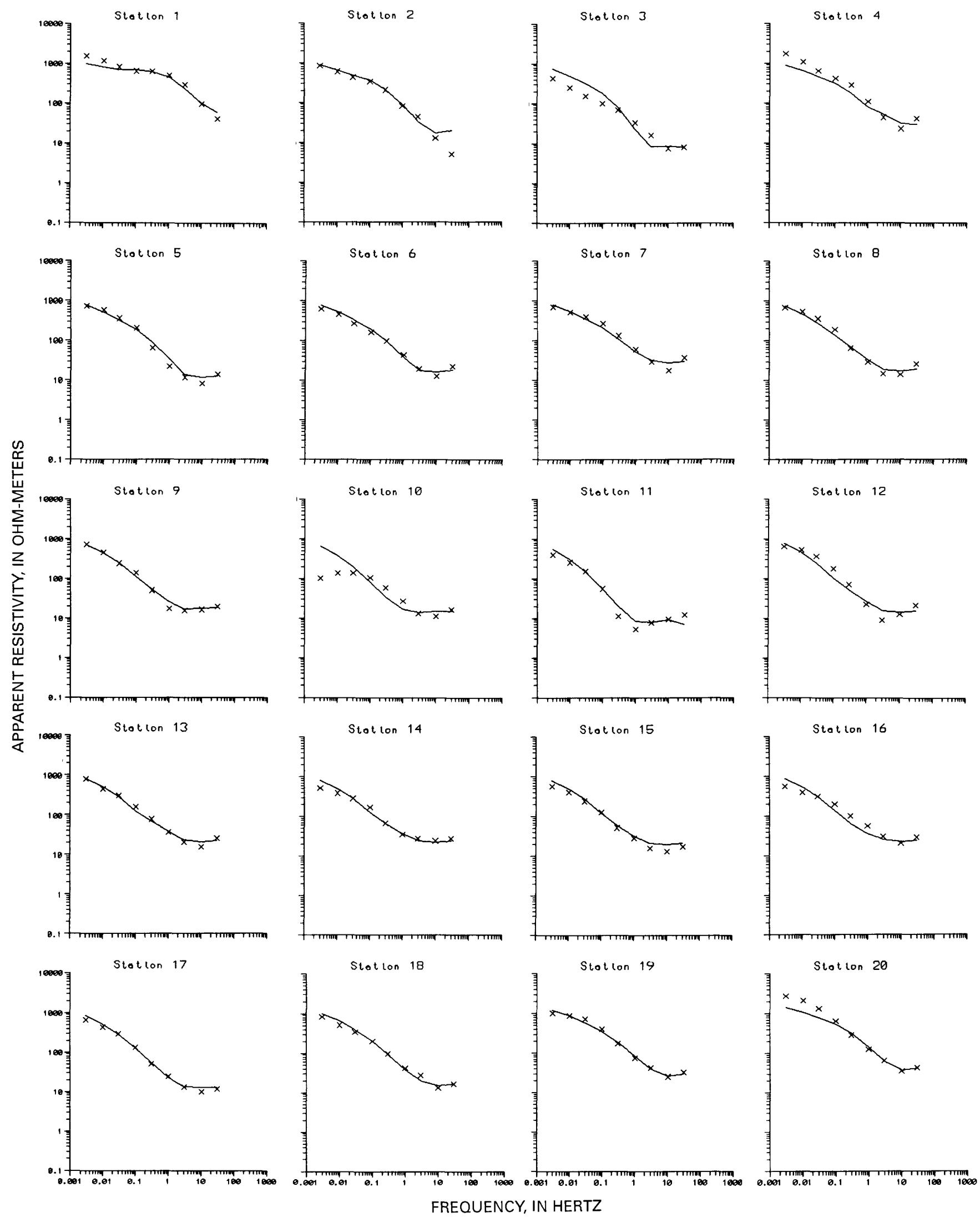

Figure B5. Resistivity plots for 20 stations along profile C-C' (see fig. 5). See Appendix A for explanation of "apparent resistivity." Increasing station numbers represent positions along the profile from west to east. 

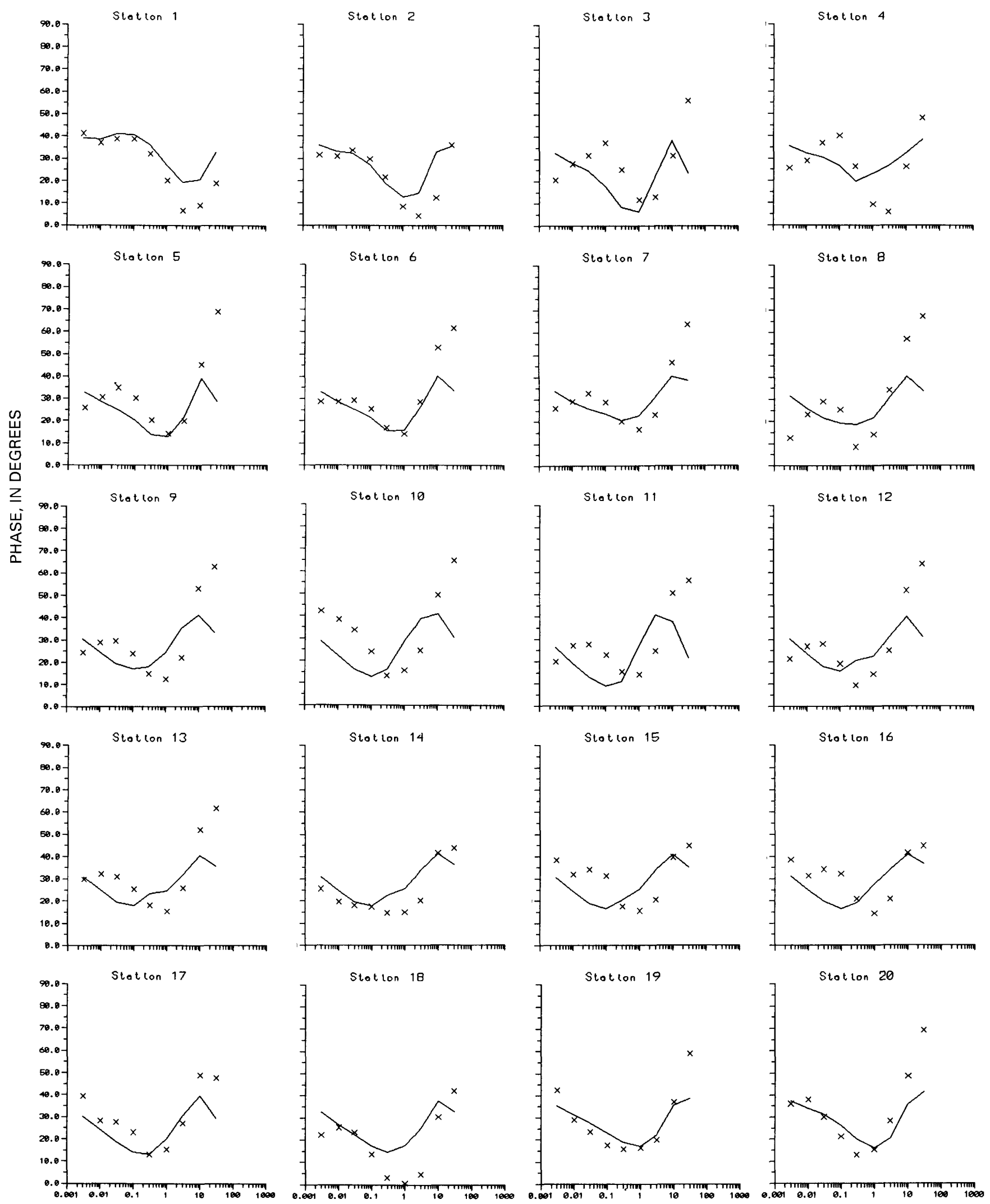

FREQUENCY, IN HERTZ

Figure B6. Phase plots for 20 stations along profile C-C' (see fig. 5). Increasing station numbers represent positions along the profile from west to east. 

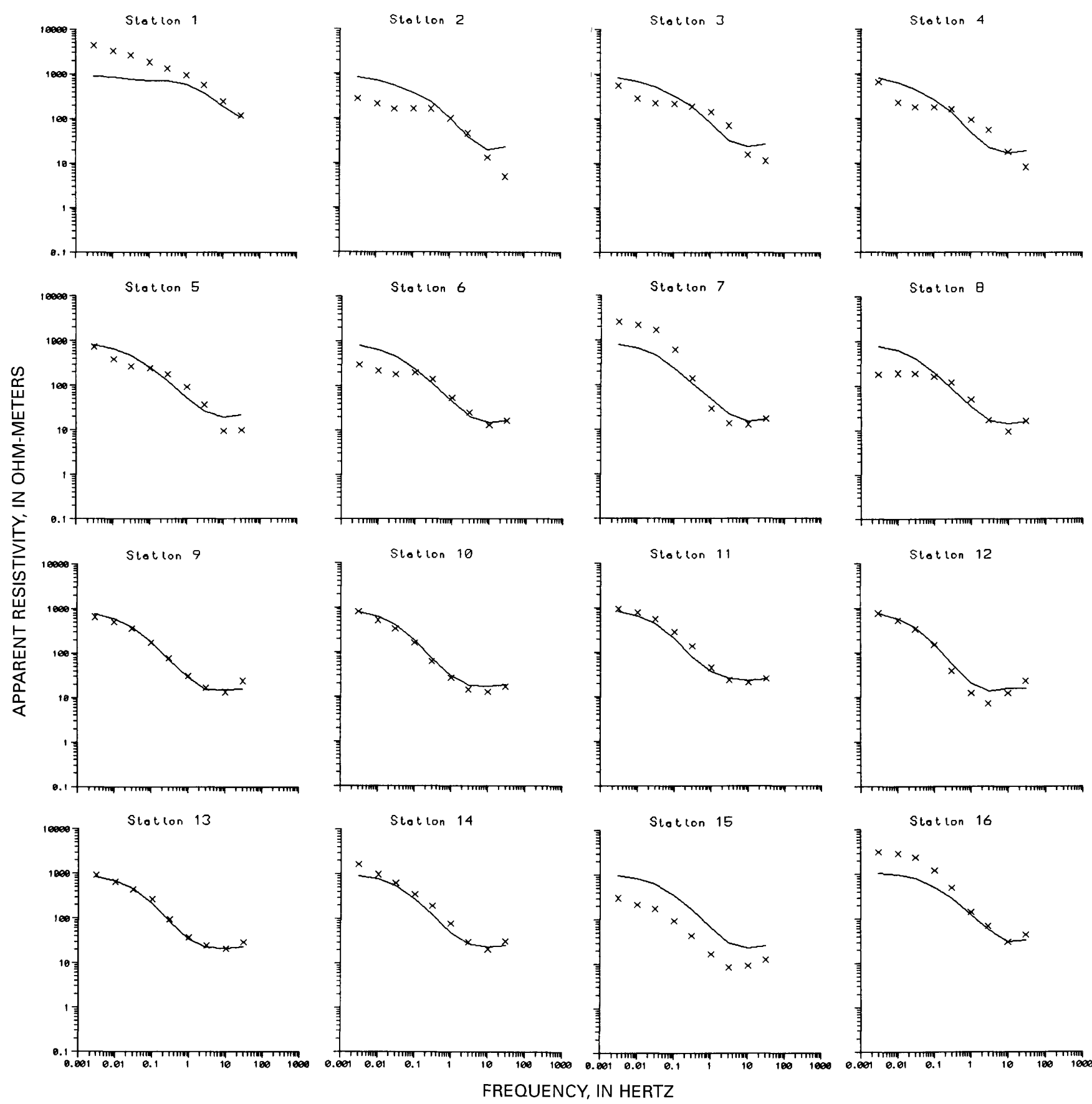

FREQUENCY, IN HERTZ

Figure B7. Resistivity plots for 16 stations along profile D-D' (see fig. 5). See Appendix A for explanation of "apparent resistivity." Increasing station numbers represent positions along the profile from west to east. 

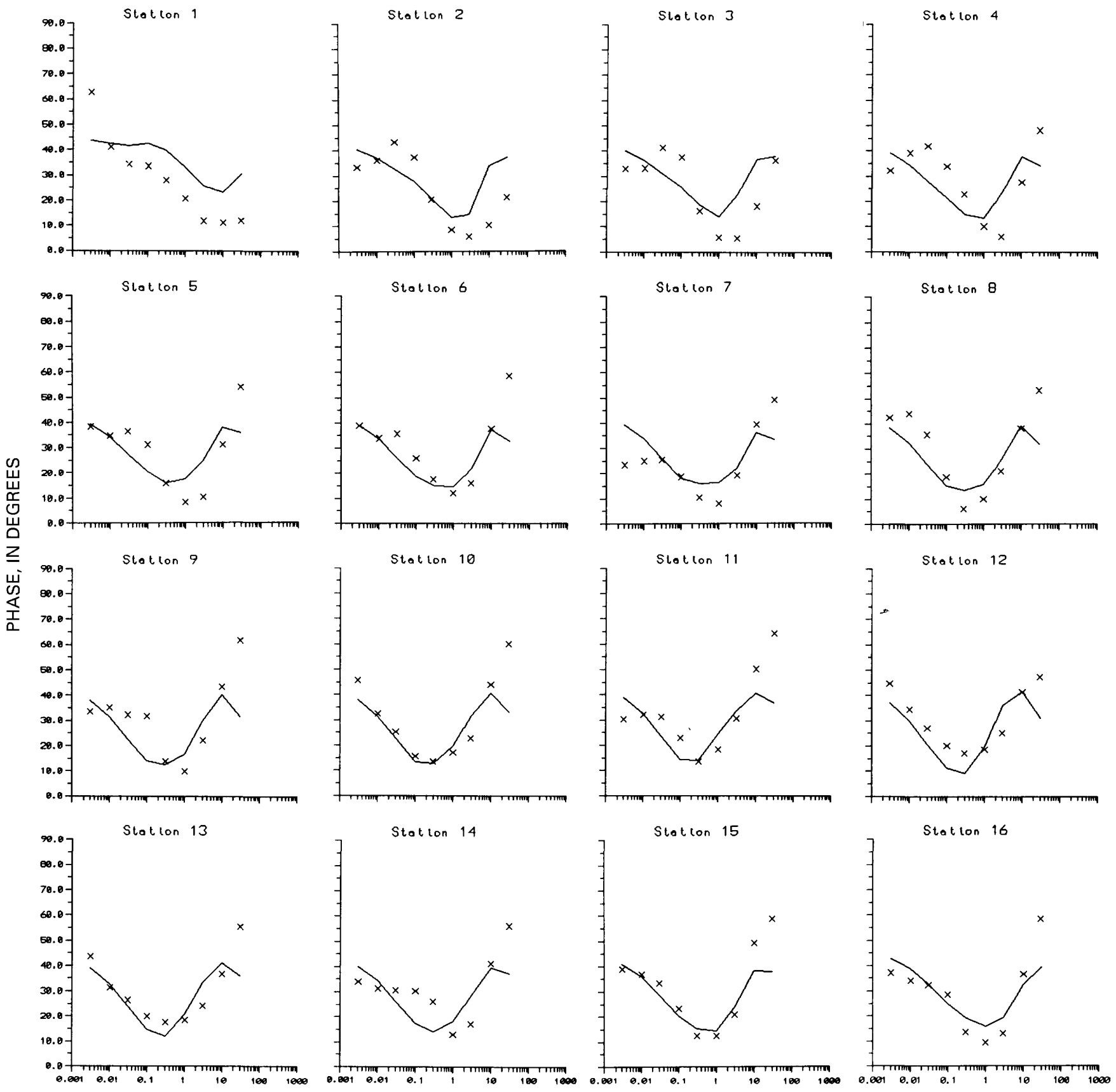

FREQUENCY, IN HERTZ

Figure B8. Phase plots for 16 stations along profile D-D' (see fig. 5). Increasing station numbers represent positions along the profile from west to east. 

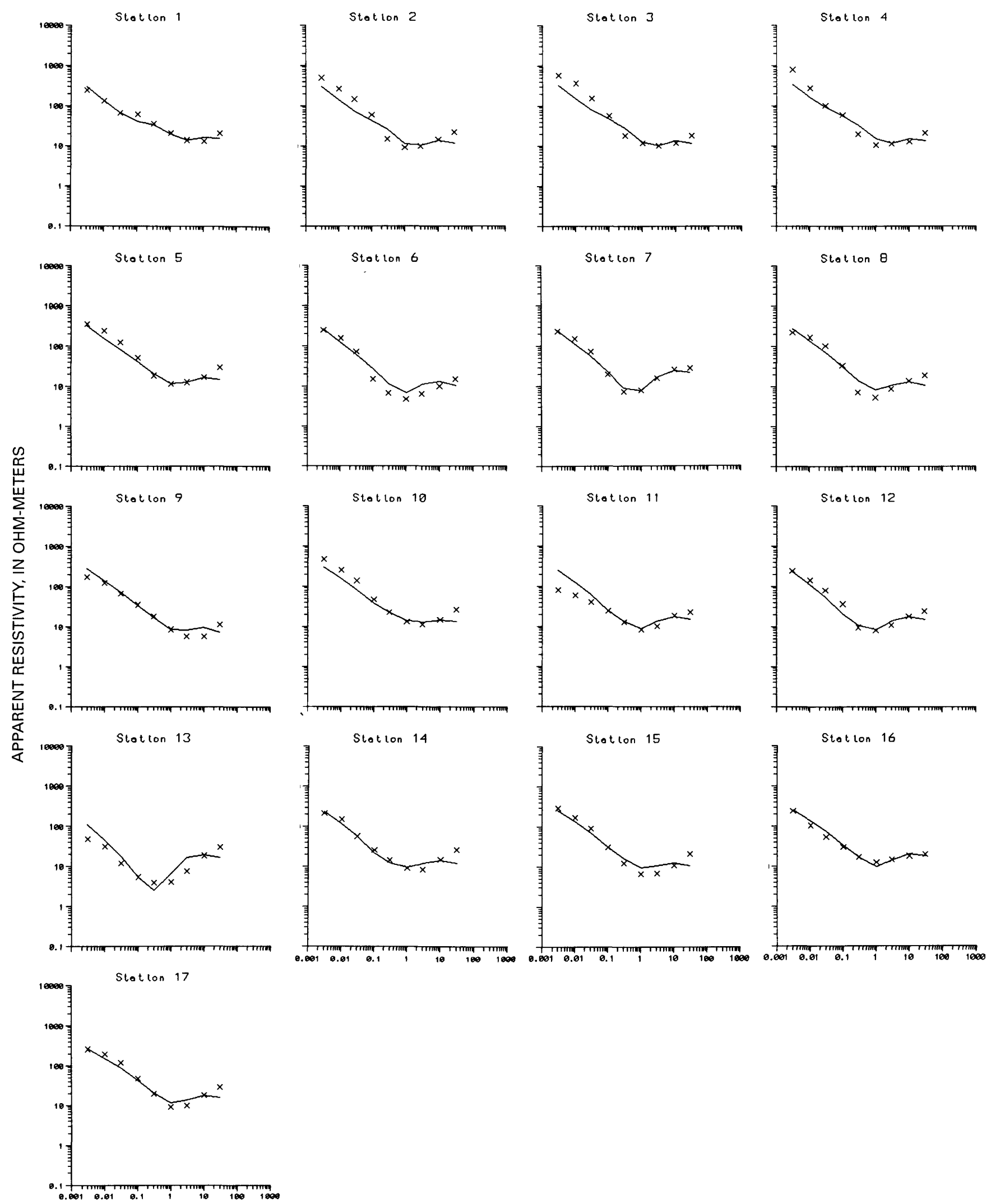

FREQUENCY, IN HERTZ

Figure B9. Resistivity plots for 17 stations along profile E-E' (see fig. 5). See Appendix A for explanation of "apparent resistivity." Increasing station numbers represent positions along the profile from north to south. 

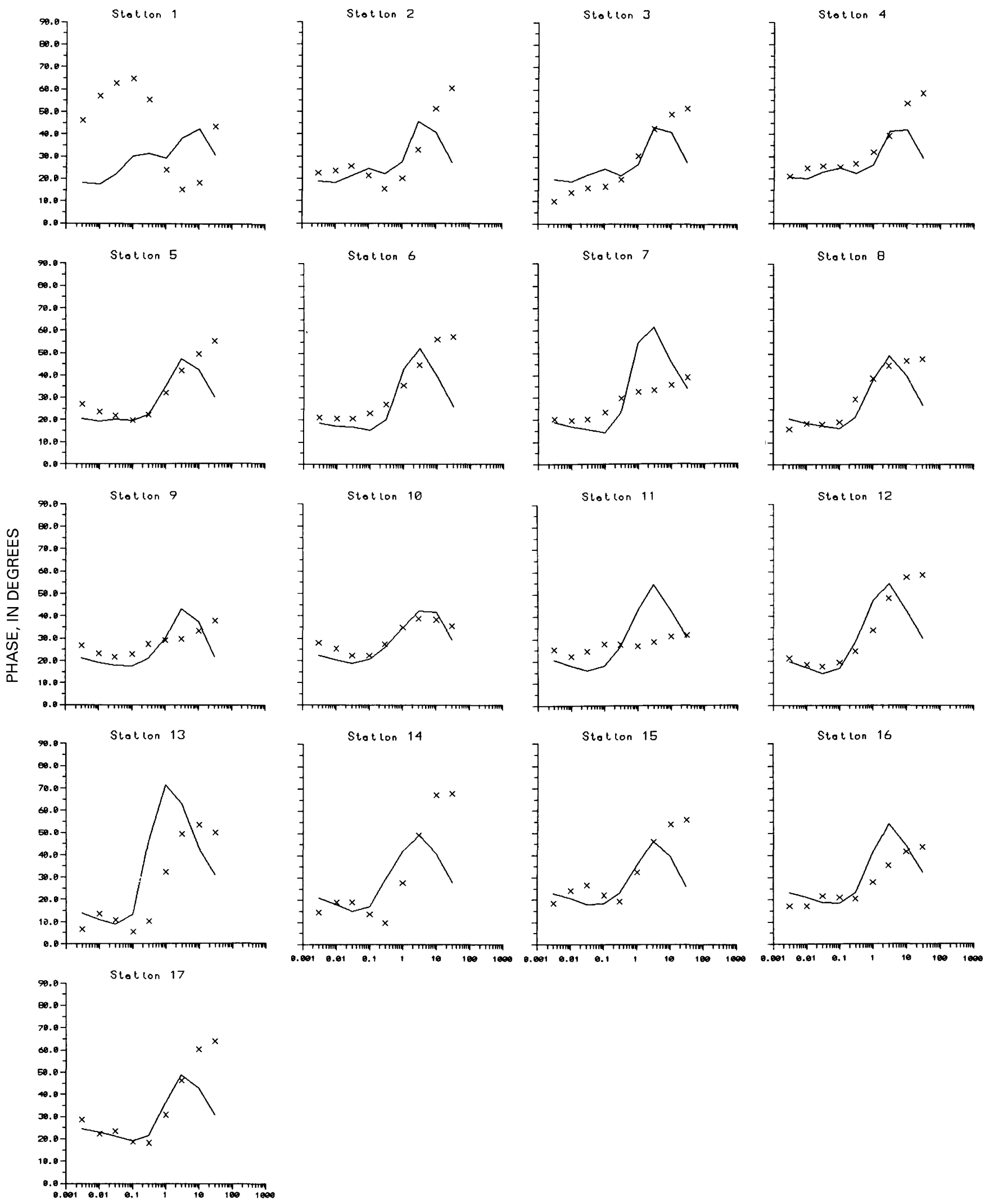

FREQUENCY, IN HERTZ

Figure B10. Phase plots for 17 stations along profile E-E' (see fig. 5). Increasing station numbers represent positions along the profile from north to south. 